\title{
Acyl anion synthons: benzotriazole stabilized compared to classical
}

\author{
Alan R. Katritzky*and Kostyantyn Kirichenko \\ Center for Heterocyclic Compounds, University of Florida, Department of Chemistry, \\ Gainesville, Florida 32611-7200, USA \\ E-mail: Katritzky@chem.ufl.edu
}

\section{Dedicated to Professor Armand Lattes to celebrate his 50 years of great research and teaching activity}

\section{Contents}

1. Introduction

2. Classical acyl anion synthons

2.1. Cyanohydrins

2.2. Azolium stabilized acyl synthons

2.3. Thioacetals

2.4. Alkyl vinyl ethers, vinyl sulfides and vinyl selenides

3. Benzotriazole stabilized acyl anion synthons

3.1. Alkyl vinyl ethers, vinyl sulfides and vinyl selenides

3.2. $N$-[Ethoxy(aryl)methyl]benzotriazoles - aroyl anion synthons

3.3. Bis(benzotriazolyl)methane derivatives

3.4. 1-(1-Methylsulfanylalkyl)benzotriazoles

3.5. 1-(Carbazolylalkyl)benzotriazoles

3.6. Application to the synthesis of 1,6-diketones

4. Propenoyl anion synthons

5. Propargoyl anion synthons

6. References and notes

\section{Introduction}

Increasing need for new methods to construct complex molecules, especially natural products with a variety of functionalities, promoted the development of strategies utilizing temporary reversal ("umpolung") of the reactivity of functional groups. This important concept was first introduced in 1962-1965 by Froling and Arens, ${ }^{1}$ Truce and Roberts, ${ }^{2}$ and Seebach and Corey ${ }^{3,4}$ in their applications of thioacetals to the synthesis of carbonyl compounds. ${ }^{5-7}$ 
The account provides a brief survey on applications of important classical acyl anion synthons to illustrate the advantages and limitations of the major methods available and then attempts to assess the utility of the diverse benzotriazole-stabilized acyl anion synthons, developed by our research group over the last 15 years. The benzotriazole moiety, which can be introduced easily to a molecule, possesses several properties that are relevant to an acyl anion synthon: especially regioselective stabilization of an $\alpha$-carbanion and ease of removal in the final stage. ${ }^{8}$ The methodology has been applied to the synthesis of a large variety of simple and functionalized alkenyl, alkynyl, aryl/heteroaryl, and alkyl ketones plus alkenoyl-, alkynoyl-, aroyl-, and heteroaroylsilanes.

\section{Classical acyl anion synthons}

\subsection{Cyanohydrins}

The venerable cyanide ion catalyzed dimerization of aromatic and heterocyclic aldehydes $\mathbf{1}$ to benzoins $\mathbf{3}$ by formation of key intermediates $\mathbf{2 b}$, which are nitrile-stabilized acyl anion synthons (Scheme 1).
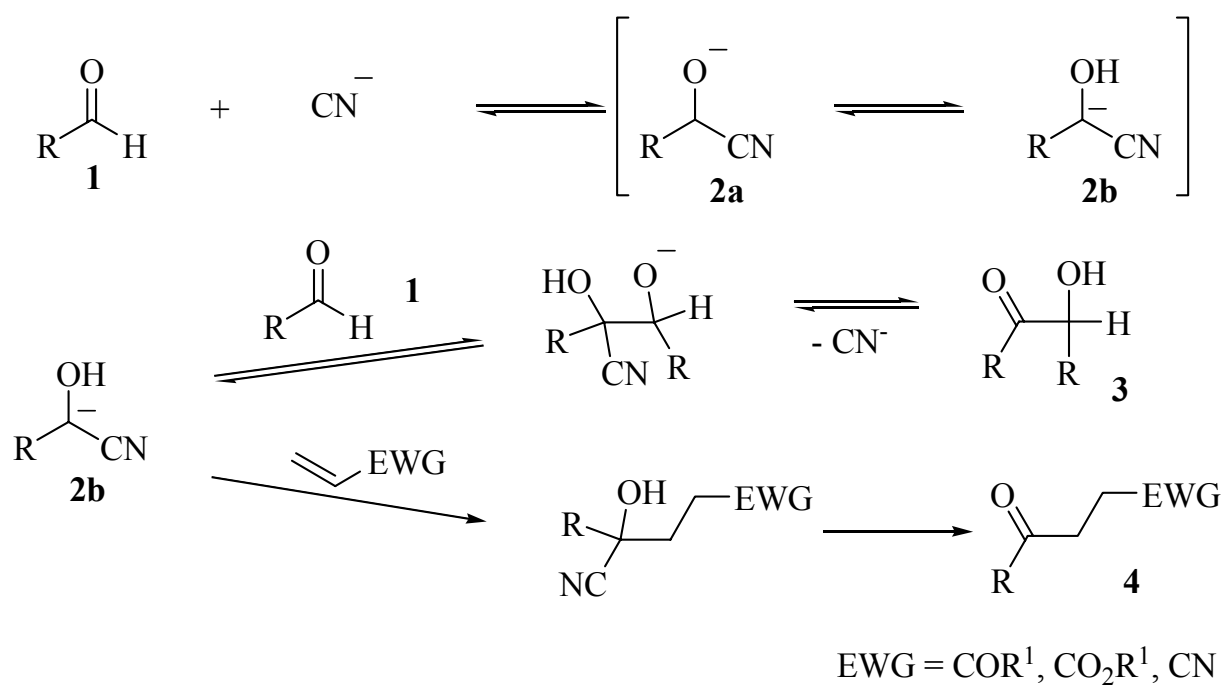

\section{Scheme 1}

Carbanions of type $\mathbf{2 b}$ add to double bonds by Michael type addition to give 1,4-diketones, 4-ketonitriles, and 4-ketoesters of general structure 4 (Scheme 1). ${ }^{9-11}$ 


\subsection{Azolium stabilized acyl synthons}

It is known that vitamin $\mathrm{B}^{1}$ (thiamine) converts aliphatic aldehydes to acyloins. The catalytic activity is associated with thiazolium part $5(\mathrm{Y}=\mathrm{S})$ of the vitamin (Scheme 2). ${ }^{12-16}$
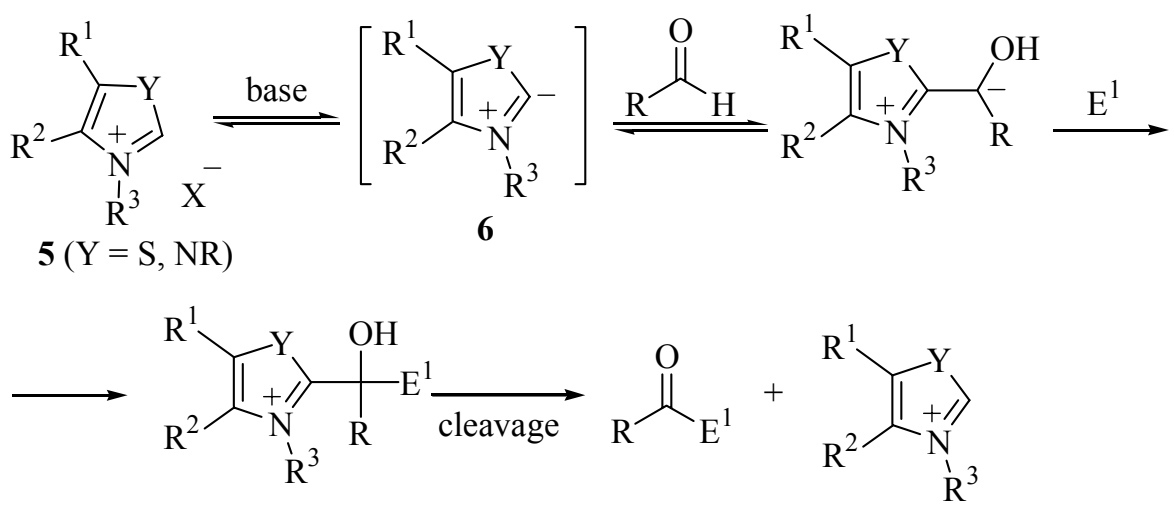

\section{Scheme 2}

Thiazolium and other azolium salts of structure 5, including imidazolium and benzimidazolium, were successfully employed as catalysts in benzoin - acyloin condensations of aliphatic and aromatic aldehydes $\mathbf{1}$ (Scheme 3$){ }^{17}$

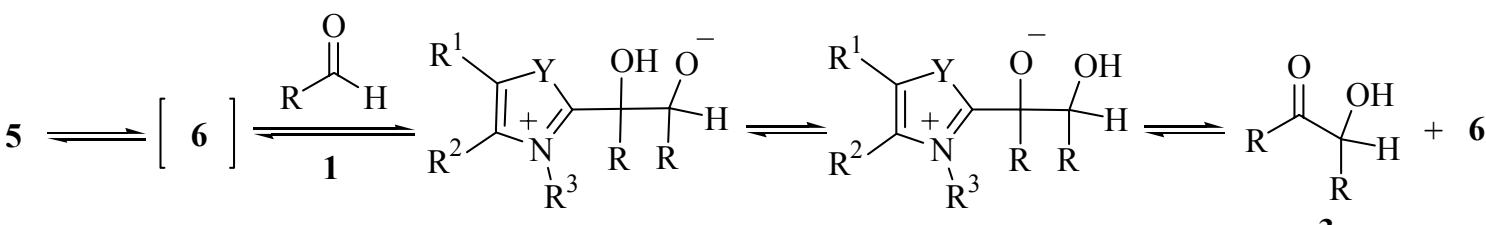

\section{Scheme 3}

Addition of aldehydes 1 to $\alpha, \beta$-unsaturated ketones, esters and nitriles of structure 7 (Scheme 4$)^{9,11}$ and similar addition of acylsilanes to $\alpha, \beta$-unsaturated ketones and esters ${ }^{18}$ in the presence of 5 provide access to carbonyl derivatives 8. Azolium 5 catalyzed syntheses of heteroaromatic ketones $\mathbf{1 0}$ and ketimines 12 (and subsequently 1,2-diketones 13) by the reaction of aldehydes 1 with heteroaryl halides $\mathbf{9}^{19}$ and imidoyl chlorides $11,{ }^{20}$ respectively, have also been reported. 


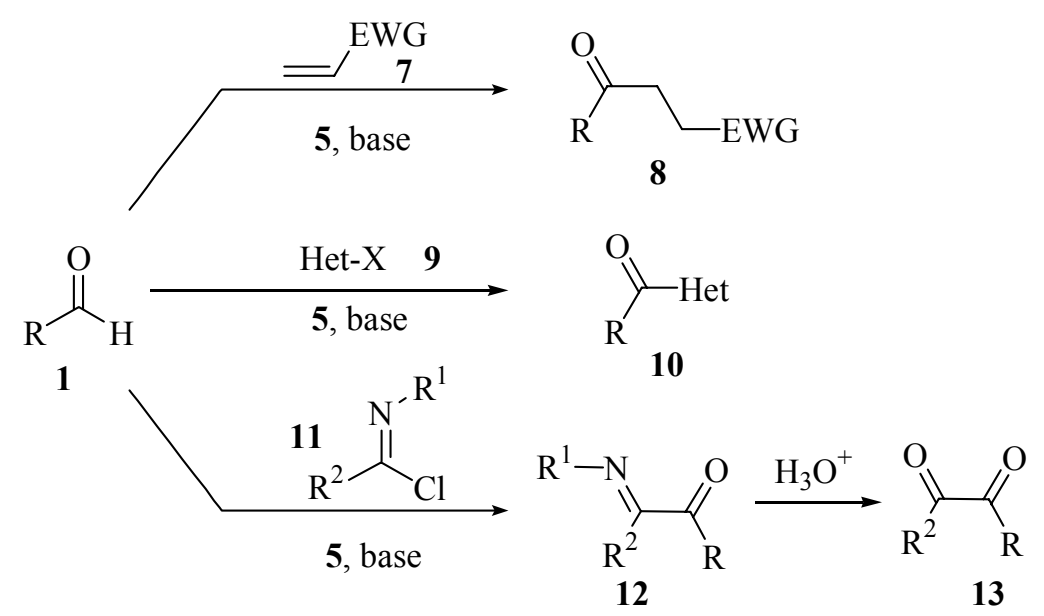

\section{Scheme 4}

\subsection{Thioacetals ${ }^{21}$}

\section{1,3-Dithianes}

The nucleophilic acylation by reaction of carbanions 15, derived from 1,3-dithianes 14, with electrophiles followed by hydrolysis of the intermediates $\mathbf{1 6}$ forming a carbonyl compound $\mathbf{1 7}$ is still the most widely used umpolung method (Scheme 5).,22

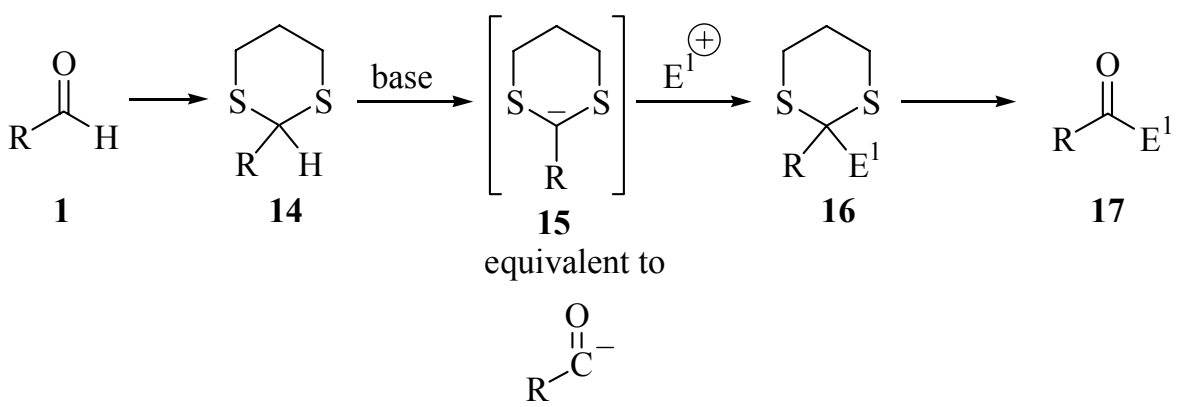

\section{Scheme 5}

1,3-Dithianes have been successfully used in reactions with (i) alkyl halides, sulfonates and triflates, ${ }^{23-28}$ (ii) oxiranes ${ }^{23,29-31}$ and three- to six-membered cyclic ethers; ${ }^{29}$ (iii) carbonyl compounds; $;^{23,32,33}$ (iv) acid halides ${ }^{34,35}$ and chloroformates; ${ }^{29,36,37}$ (v) imines; ${ }^{23}$ and (vi) electron deficient olefins ${ }^{38-40}$ (Scheme 6). 

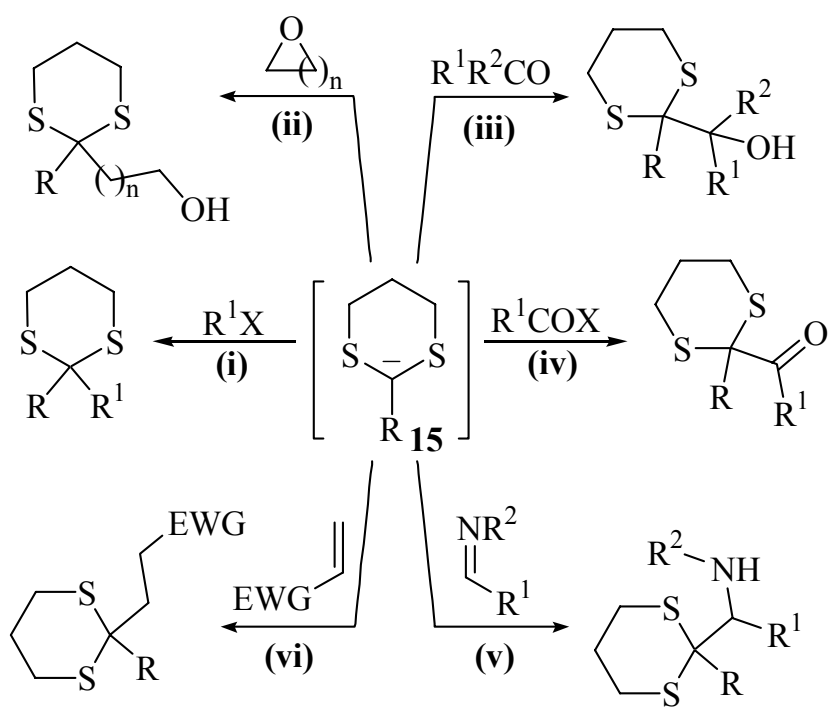

\section{Scheme 6}

Unfortunately, the hydrolysis of 1,3-dithianes under mild conditions has proved difficult. High yields of carbonyl compounds were reported in the presence of mercury (II), ${ }^{25-27,31,38}$ in few cases with copper (II) ions, ${ }^{32}$ or by oxidation (see later).

\section{Bis(alkylthio)acetals}

Alkylation of bis(alkylthio)acetals 18 (Scheme 7) using an alkali metal amide followed by reaction with electrophiles occurs in low yields. ${ }^{1}$ However, an alternative approach involving initial addition of a Grignard reagent to a dithioester 19 followed by reaction of anion 20 with an electrophile (ketones, aldehydes and chloroformates) is a useful synthetic method. Thus $\alpha$ hydroxy ketones and $\alpha$-ketoesters were obtained in good yield but required mercuric ion promoted hydrolysis of thioketals 2 . $^{41}$
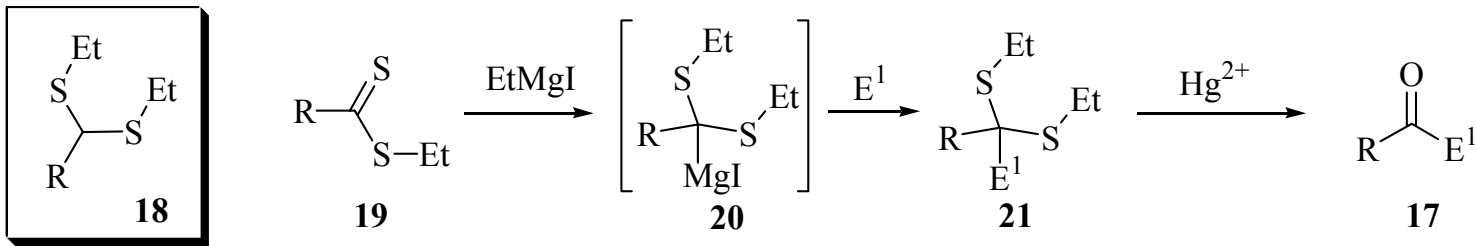

\section{Scheme 7}

\section{Bis(arylthio)acetals}

The use of bis(phenylthio) acetals 22 rather than bis(alkylthio) acetals $\mathbf{1 8}$ results in increased anion 23 stabilization (Scheme 8). Initial studies employed alkali metal amides in liquid ammonia and showed satisfactory results only with alkyl halides. ${ }^{1}$ Later, alternative procedures using lithiation of $\mathbf{2 2}$ with butyllithium in the presence of TMEDA ${ }^{42,43}$ and a copper derivative of 
$\mathbf{2 3}^{44}$ were introduced. Anions 23 were successfully reacted with alkyl halides, ${ }^{2,43,45}$ aldehydes and ketones, ${ }^{42,43,46,47}$ acid chlorides, ${ }^{42}$ and electron deficient olefins. ${ }^{44,48,49}$ However, butyllithium caused carbon - sulfur bond cleavage. ${ }^{43,50}$ Similarly with thioketals $\mathbf{1 6}$ and $\mathbf{2 1}$, hydrolysis of $\mathbf{2 4}$ to ketones 17 requires heavy metal catalysis $\left(\mathrm{Hg}^{2+}, \mathrm{Cu}^{2+}, \mathrm{Ga}^{3+}\right){ }^{44,45,51}$ Hydrolysis intermediates 21 with TFA was also reported, but caused in some cases elimination of phenylthio group instead to give a vinyl sulfide. ${ }^{42}$

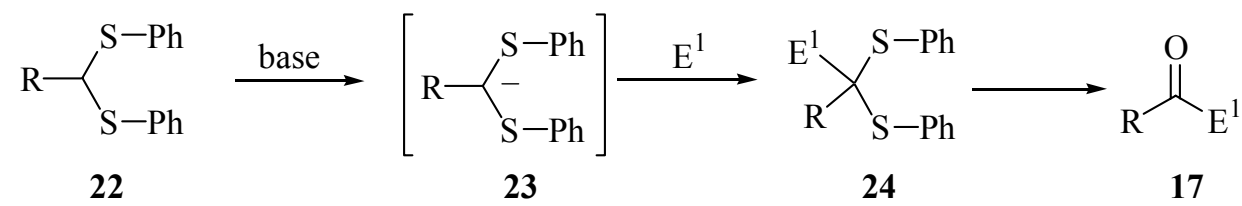

\section{Scheme 8}

\section{Oxidized thioacetals}

Oxidation of a dithioacetal sulfur atom facilitates generation of a carbanion. Methyl methylthiomethyl sulfoxide 25a, ethyl ethylthiomethyl sulfoxide $\mathbf{2 5 b}$ and 1,3-dithiane-1-oxide 25c have been employed as acyl anion equivalents for the preparation of ketones (Scheme 9). Acyl anion synthon 25a $(\mathrm{R}=\mathrm{H})$ was used for the preparation of symmetrical ${ }^{52,53}$ and cyclic ${ }^{54,55}$ ketones by reaction with excess base $(\mathrm{NaH}, \mathrm{KH})$ and an alkyl halide or a dihaloalkane, respectively. The preparation of $\alpha$-hydroxyketones has been achieved by the reaction of $25 \mathbf{a}(\mathrm{R}=$ alkyl) with LDA and aldehydes. ${ }^{56}$ Reagent $25 \mathbf{b}(\mathrm{R}=\mathrm{H})$ enabled the preparation of unsymmetrical ketones $\mathbf{2 8}$ via sequential alkylation with a base (BuLi or LDA) and an alkyl halide. ${ }^{57}$ In the reactions with $\alpha, \beta$-unsaturated ketones and esters, conjugate addition of lithiated 25b $\left(\mathrm{R}=\right.$ alkyl) dominated to give 1,4-dicarbonyl systems. ${ }^{58}$ 2-Substituted 1,3-dithiane-1-oxides 25c were readily deprotonated with LDA followed by reaction with a variety of electrophiles, including alkyl halides, aldehydes, and ketones. ${ }^{59}$

Adducts 26 and 27 were converted to ketones 17 and 28 by acidic hydrolysis using hydrochloric acid, ${ }^{52}$ or perchloric acid, ${ }^{57,59}$ and in the presence of a mercury salt to avoid formation of disulfides. ${ }^{57,58}$

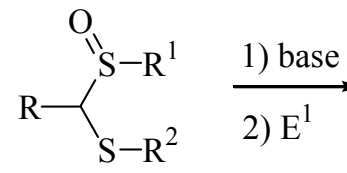

25a $R^{1}, R^{2}=M e$

25b $\mathrm{R}^{1}, \mathrm{R}^{2}=\mathrm{Et}$

25c $\mathrm{R}^{1}, \mathrm{R}^{2}=-\left(\mathrm{CH}_{2}\right)_{3}$ -

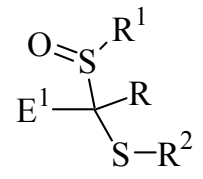

26

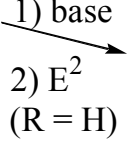<smiles>[R]C(=O)[I-][I+]</smiles><smiles>[R]SC(F)(F)S([R])=O</smiles>

27

\section{Scheme 9}




\section{Hydrolysis of dithioketals}

Hydrolysis of the dithioacetal (ketal) group to a carbonyl group ${ }^{21,60}$ is the crucial stage and often extremely difficult to achieve, especially for compounds having complex structure and sensitive groups. ${ }^{61,62}$ The problem is that the equilibria of Scheme 10 favor the dithioketal by large factors and only methods which remove the thiol products irreversibly are suitable for the hydrolysis.

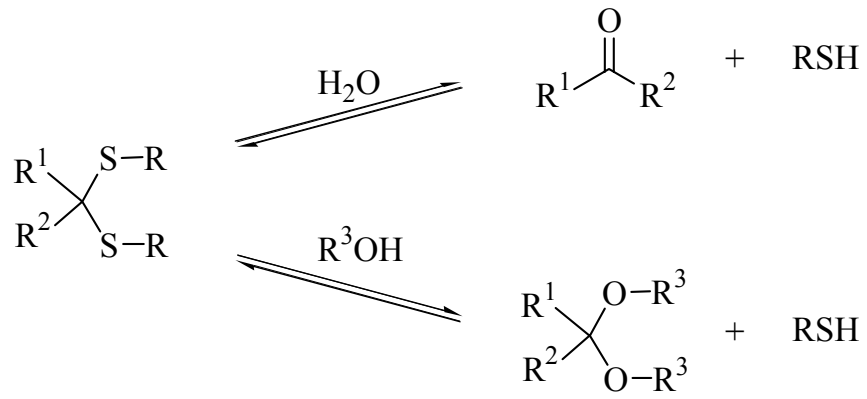

\section{Scheme 10}

Frequently utilized procedures for hydrolysis are (i) transition metal ion $(\mathrm{Hg}, \mathrm{Ag}, \mathrm{Cd}, \mathrm{Cu}$, $\mathrm{Ga}$ ) induced hydrolysis, which involves metal thiolate formation; (ii) oxidation of sulfur to make it less nucleophilic; (iii) alkylation (typically with methyl iodide, trimethyl(or ethyl)oxonium tetrafluoroborate, methyl fluorosulfonate or trityl methyl ether) to a sulfonium salt followed by elimination of sulfide in the presence of base; and (iv) transacetalization to highly reactive carbonyl derivatives using formaldehyde, glyoxylic acid, ${ }^{62,63}$ or benzaldehydes. ${ }^{64}$

Trityl methyl ether in the presence of catalytic trityl perchlorate was reported to cleave selectively a diethyl thioketal in the presence of a diphenyl thioketal or 1,3-dithiane. ${ }^{65}$ Interestingly, gallium chloride mediated hydrolysis affords transformation of dithioketals into the corresponding ketones whereas dithianes and dithioacetals of aldehydes were unreactive. ${ }^{51}$

\subsection{Alkyl vinyl ethers, vinyl sulfides and vinyl selenides}

Alkyl vinyl ethers 29 have been used as acyl anion equivalents (Scheme 11). ${ }^{66-71}$ Deprotonation of 29 requires the use of tert-butyllithium, ${ }^{66-73}$ in some cases in the presence of $\mathrm{HMPA}^{72}$ or TMEDA. ${ }^{66,67,71}$ The system $n$-butyllithium / $\mathrm{KOBu}^{t}$ has also been reported to be suitable for the deprotonation of 1,3-dienyl ethers. ${ }^{74}$ Reactions of carbanions 30 with alkyl halides, ${ }^{67,72,74}$ aldehydes, ${ }^{66,67,74}$ ketones, ${ }^{67,73}$ esters, ${ }^{67}$ benzonitrile, ${ }^{67}$ and alkyl silyl, ${ }^{68,69,71}$ alkyl germanium ${ }^{68,69}$ and alkyl tin ${ }^{69}$ chlorides yield intermediates 31, which can be hydrolyzed to the corresponding ketones $\mathbf{3 2}$ by aqueous acid, ${ }^{67-71}$ also in the presence of mercury ion. ${ }^{66}$

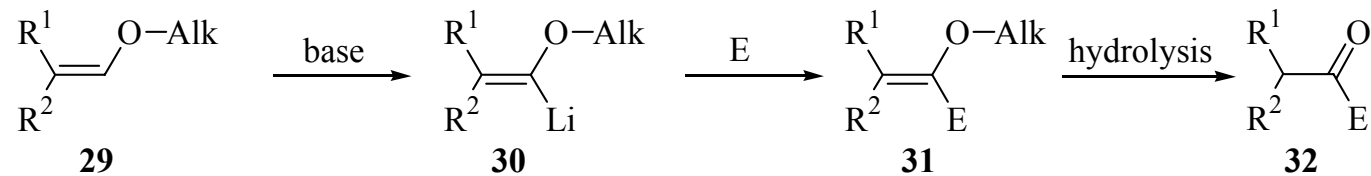

Scheme 11 
In a similar manner, vinyl sulfides $33\left(\mathrm{R}^{3}=\right.$ alkyl, phenyl) have been used as synthons for the preparation of ketones (Scheme 12).$^{70,75-77}$ The base / solvent systems used for the generation of vinylanion 34 are: $n$-butyllithium in THF, ${ }^{70}$ sec-butyllithium ${ }^{75}$ in THF - HMPA and $n$ butyllithium / potassium tert-butoxide ${ }^{74,76,77}$ for alkyl vinyl sulfides $\left(\mathrm{R}^{3}=\right.$ alkyl); and $n$ butyllithium - TMEDA, ${ }^{78} \mathrm{LDA}^{79-81}$ and $\mathrm{LTMP}^{82}$ for aryl vinyl sulfides $\left(\mathrm{R}^{3}=\mathrm{Ph}\right)$. In some cases treatment of phenyl sulfides $\mathbf{3 3}$ with organolithium reagents resulted in side reactions involving addition to the double bond ${ }^{80,82,83}$ and ortho-lithiation ${ }^{82}$ of the phenyl ring. Vinyl anion 34 reacts with alkyl halides, ${ }^{74-77}$ aldehydes, ${ }^{74,75,81}$ acid chlorides, ${ }^{81}$ epoxides, ${ }^{75}$ trimethylsilyl chloride ${ }^{76,77}$ and iminium salts ${ }^{70}$ to give masked ketones 35 that may be hydrolyzed to ketones $\mathbf{3 2}$ by methods that have been used for the hydrolysis of thioacetals, using mercury salts, ${ }^{25,75,84}$ titanium tetrachloride, ${ }^{70,79,84-86}$ TFA $^{79}$ or methyl iodide ${ }^{76,77}$ in aqueous acetonitrile. Hydrolysis of 35 sometimes proved difficult ${ }^{79}$ and in some cases the vinyl sulfides could not be hydrolyzed even using mercury salts. ${ }^{70}$

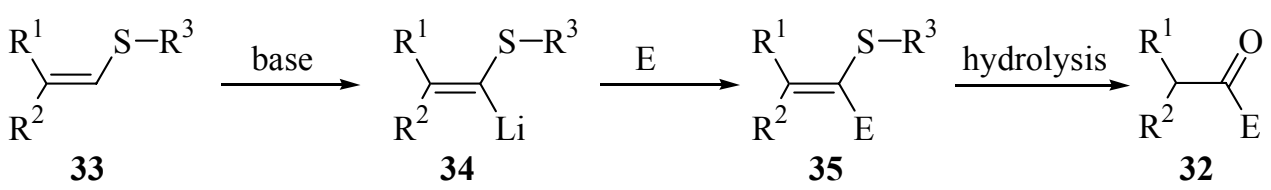

\section{Scheme 12}

1-(Phenylseleno)alkenes 36 on treatment with butyllithium at $-78{ }^{\circ} \mathrm{C}$ gave products of metalation, cleavage of the $\mathrm{C}-\mathrm{Se}$ bond and addition (Scheme 13). ${ }^{87} \mathrm{LDA}$ was found to be an effective reagent for metalation of $\mathbf{3 6}$, but depending on reaction conditions, elimination of phenylselenol with formation of acetylene was observed as well as metalation. ${ }^{87}$ Surprisingly, the treatment of 1-(phenylseleno)alkenes 36 with a mixture of potassium diisopropylamide - lithium tert-butoxide (KDA) gave selenium stabilized carbanions 37 , which reacted with a variety of electrophiles including alkyl halides, epoxides, aldehydes, and ketones to give products $\mathbf{3 8}$ in good yields. ${ }^{88}$ Hydrolysis of vinyl selenides $\mathbf{3 8}$ to the corresponding ketones $\mathbf{3 2}$ was accomplished in the presence of mercury salts, ${ }^{88-91}$ strong mineral acids or TFA. ${ }^{92,93}$

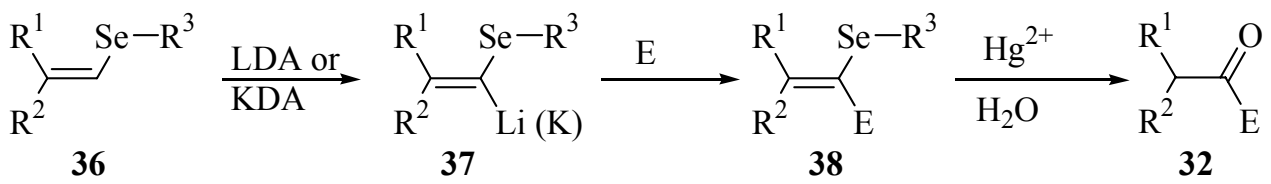

\section{Scheme 13}




\section{Benzotriazole stabilized acyl anion synthons}

Over the last 15 years a range of benzotriazole-stabilized acyl anion synthons has been developed (Figure 1). These synthons, obtained by deprotonation of 39-43, combine the stabilizing influence of a benzotriazolyl group and $\alpha$-phenoxy-, $\alpha$-alkoxy-, $\alpha$-mercapto-, $\alpha$ carbazolyl-group, or a second $\alpha$-benzotriazolyl group.<smiles>[R]C(O)Br</smiles>

39<smiles>[R]C(Br)O[AlH2]</smiles>

40<smiles>[R]C(C)Br</smiles>

41<smiles>[R]C([Ge])Br</smiles>

42<smiles>[R]C(Br)Br</smiles>

43<smiles>Cn1c2ccccc2c2ccccc21</smiles><smiles>Cn1nnc2ccccc21</smiles>

Figure 1. Conjugate acids of benzotriazole stabilized acyl anion synthons.

\subsection{Alkyl vinyl ethers, vinyl sulfides and vinyl selenides}

1-(1-Phenoxyalkyl)benzotriazoles 39 usefully combine the activating influence of the phenoxyand benzotriazolyl- groups (Scheme 14). ${ }^{94}$ Compounds 39 are conveniently prepared in good yields (i) from 1-phenoxymethylbenzotriazole $44^{95,96}$ via lithiation with butyllithium in THF at $-78{ }^{\circ} \mathrm{C}$ followed by the reactions with alkyl halides, ${ }^{94,96,97}$ or (ii) by the $O$-alkylation of phenol with 1-(1-chloroalkyl)benzotriazoles 45 in the presence of a base. ${ }^{94,98-100}$ Compounds 39 can be deprotonated using butyllithium in THF at $-78{ }^{\circ} \mathrm{C}$ to give anions 46 , which react with a wide variety of electrophiles to give simple alkyl 47, $\alpha$-hydroxyalkyl 49, and $\alpha$-aminoalkyl 51 masked ketones. $^{94}$ Crude intermediates $\mathbf{4 7 , 4 9}$ and $\mathbf{5 1}$ are then hydrolyzed with $5 \%$ sulfuric acid in aqueous ethanol under reflux to give good overall yields of ketones $\mathbf{4 8 , 5 0}$ and $\mathbf{5 2}$, respectively.

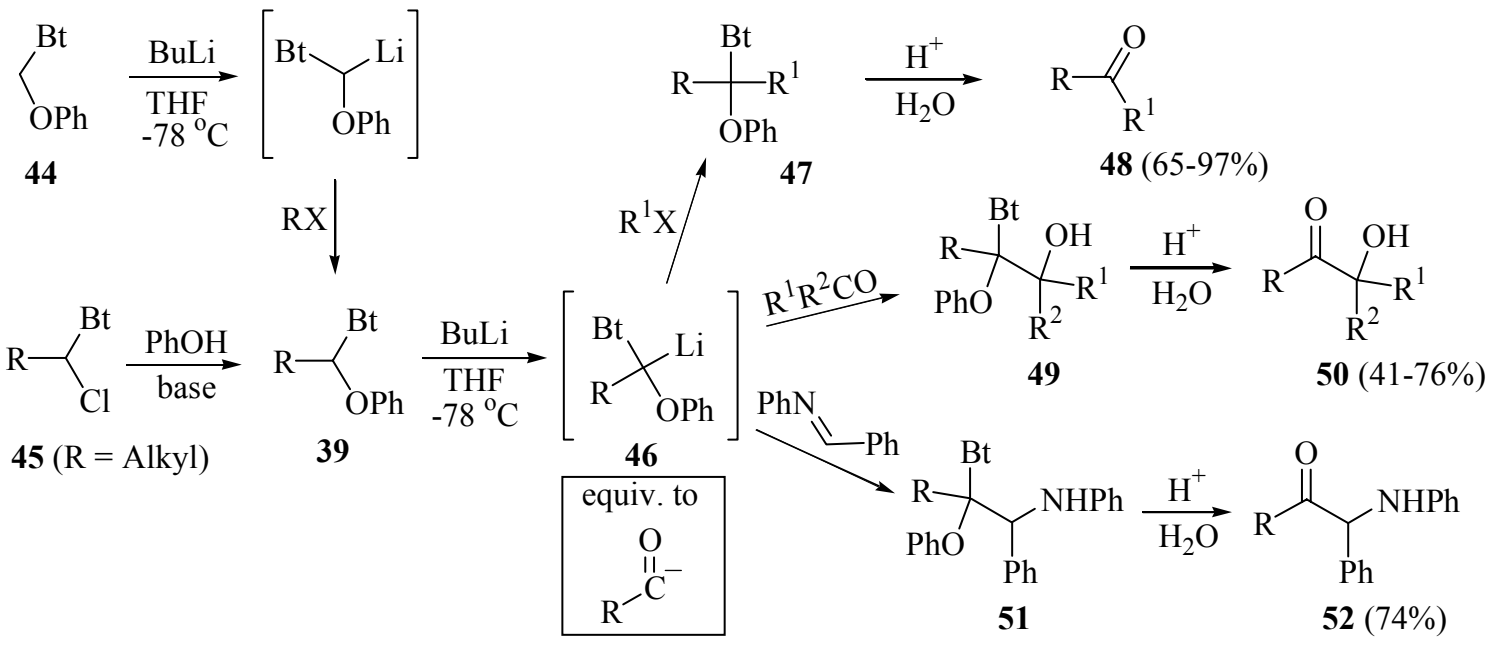

\section{Scheme 14}


1-Phenoxymethylbenzotriazole 44 was also applied to one-pot double-lithiation techniques. Successive treatment of $\mathbf{4 4}$ with one equivalent of butyllithium followed by one equivalent of alkyl halide or trialkylsilyl chloride $\left(\mathrm{R}=\mathrm{Alk}_{3} \mathrm{Si}\right)$, then with a second equivalent of butyllithium and finally, with the appropriate second electrophile (alkyl halide, aldehyde, ketone, trialkylsilyl chloride, etc) gave i good yields of ketones 48,50 and acyl silanes $48\left(\mathrm{R}\right.$ or $\mathrm{R}^{1}=$ $\mathrm{Alk}_{3} \mathrm{Si}$ ) after direct hydrolysis of crude products 47 and 49.

With $\alpha, \beta$-unsaturated ketone, 2-cyclohexenone, anion 53 gave exclusively the product of 1,4-addition 54 in 48\% yield (Scheme 15). No 1,2-addition product was detected. Intermediate $\mathbf{5 4}$ was hydrolyzed to $\mathbf{5 5}$ in $90 \%$ yield under conditions similar with those used for $\mathbf{4 8}$.

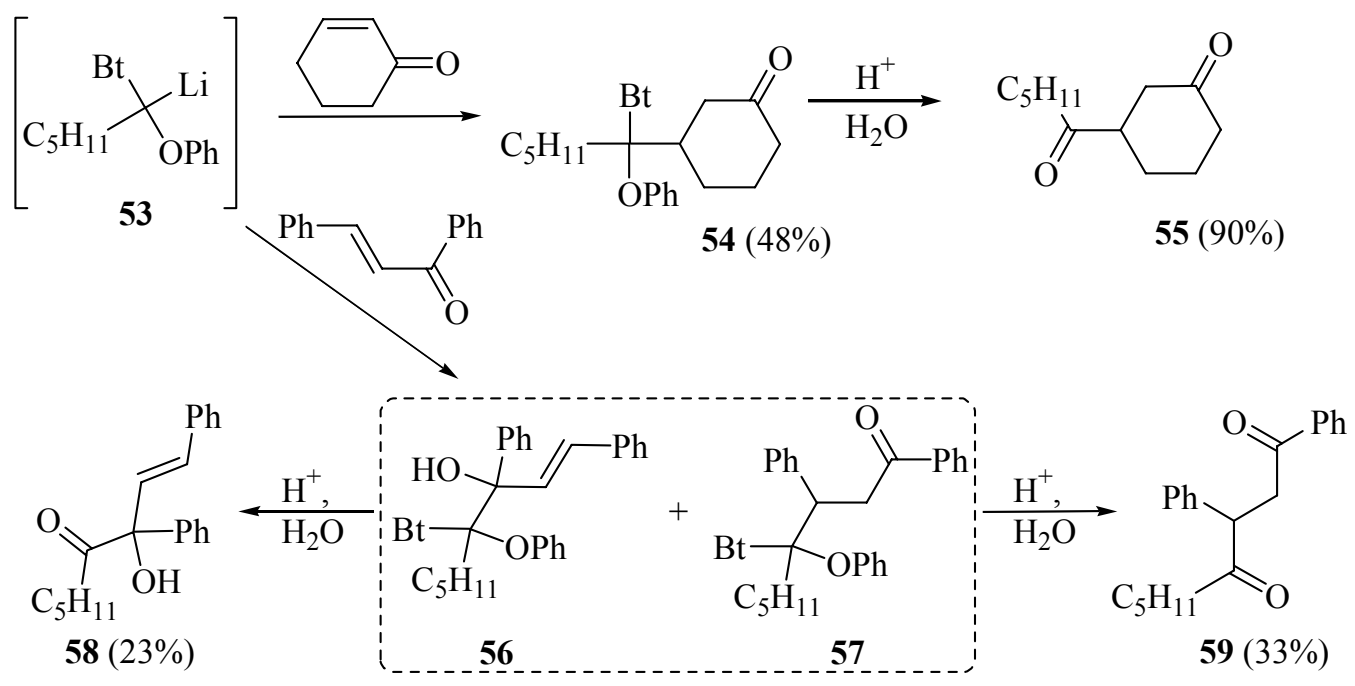

\section{Scheme 15}

However, when trans-chalcone was used as electrophile to react with anion 53, both the 1,2-addition 56 and the 1,4- addition products 57 were generated, probably as result of steric hindrance at the $\gamma$-position in chalcone (Scheme 15). The crude mixture of 56/57 was hydrolyzed with $5 \%$ sulfuric acid in aqueous ethanol to give ketones $\mathbf{5 8}(23 \%)$ and $\mathbf{5 9}(33 \%)$.

$\beta$-Alkoxy synthons from alkoxymethylbenzotriazoles and phenyl vinyl ether. $\alpha^{\prime}$-Functionalized $\beta$-alkoxy ketones

An example of the double-addition of Bt-reagents to enol ethers is shown on Scheme 16. Thus, 1-(1-alkoxy-1-arylmethyl)benzotriazoles $\mathbf{6 0}$ (available from aromatic aldehydes and benzotriazole with the corresponding alcohol, or trimethyl or triethyl orthoformate ${ }^{101-105}$ add via the ionized form, 61, to phenyl vinyl ether to give intermediate $\beta$-alkoxy acyl anion synthon 62, ${ }^{106}$ of type 39 (Figure 1) and discussed earlier (Scheme 14 and 15).

Compounds 62 can be deprotonated with butyllithium in $\mathrm{THF}$ at $-78{ }^{\circ} \mathrm{C}$ and then reacted with a variety of electrophiles to give intermediates 64, 66, 68, and 70 (Scheme 16). Reaction of anions 63 with alkyl halides gave good yields of masked ketones 64. In the reactions with 
carbonyl compounds, aromatic, benzophenone and benzaldehyde, gave excellent (83-90\%) yields of intermediates 66, while reactions with enolizable aliphatic ketones, acetone and cyclohexanone, resulted in low yields of $66\left(24-45 \%, \mathrm{R}^{1}, \mathrm{R}^{2}=\mathrm{Me},-\left(\mathrm{CH}_{2}\right)_{5}{ }^{-}\right)$and recovery of about $50 \%$ of 62 . Reactions of anion $63(\mathrm{Ar}=\mathrm{Ph}, \mathrm{Alk}=\mathrm{Et})$ with 4-methylbenzylideneaniline or TMS chloride produced masked $\alpha$-anilino ketone $\mathbf{6 8}$ and acyl trimethylsilane 70, respectively. ${ }^{106}$

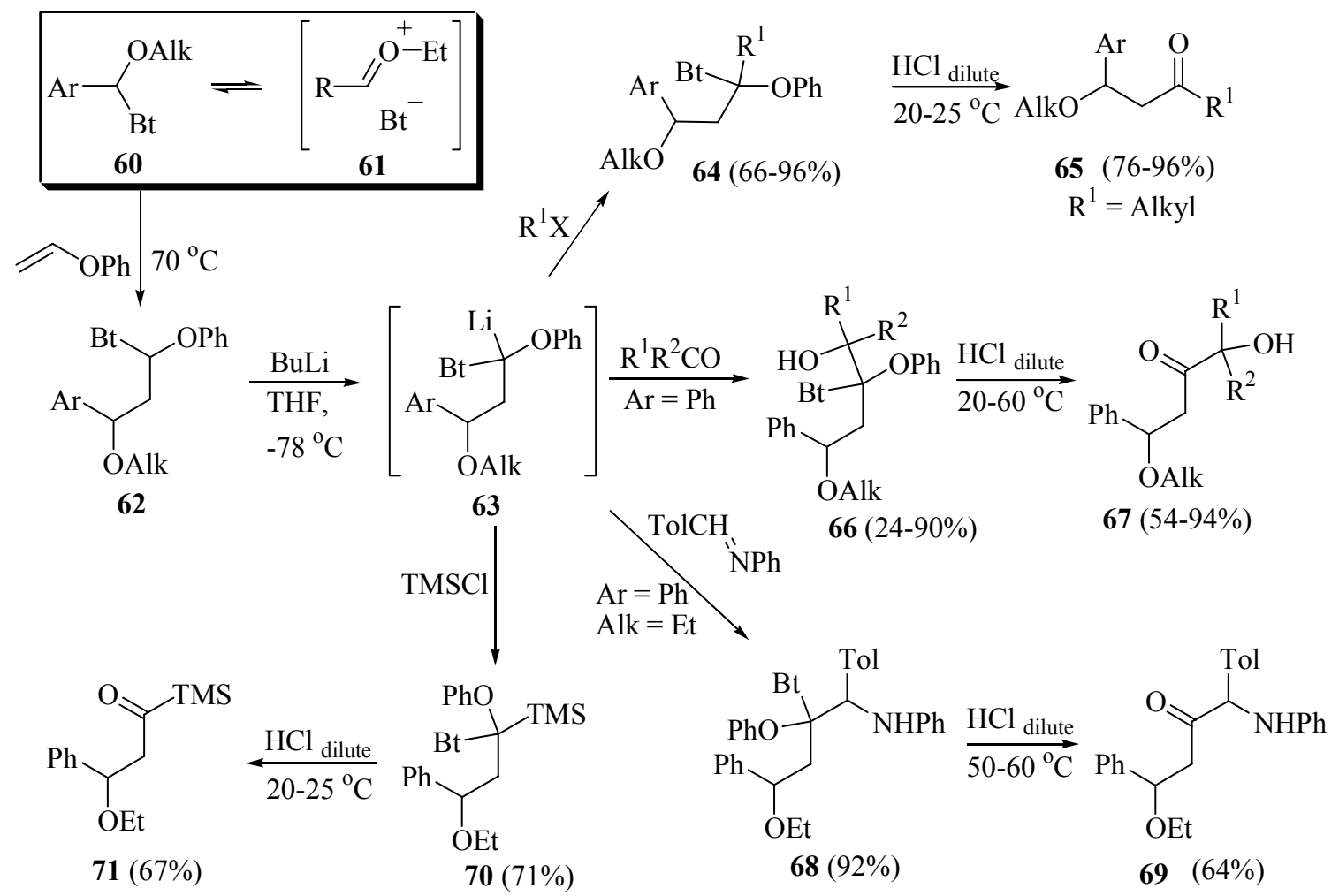

\section{Scheme 16}

Hydrolysis of compounds 64 with dilute hydrochloric acid in aqueous ethanol (1:1) at room temperature produced $\beta$-alkoxy-substituted ketones 65 in 76-96\% yields. Compound 70 under the same conditions gave 71, while hydrolysis at $50-60{ }^{\circ} \mathrm{C}$ resulted in partial deethoxylation. Unlike compounds 64 and 70, hydrolysis of intermediate 68 and some adducts 66 to ketones 69 and 67 required elevated temperature and was achieved with dilute hydrochloric acid in aqueous ethanol at $50-60{ }^{\circ} \mathrm{C} .{ }^{106}$

Reactions of anion $63(\mathrm{Ar}=\mathrm{Ph}, \mathrm{Alk}=\mathrm{Et})$ with i-propyl isocyanate and phenyl isothiocyanate gave excellent yields of corresponding adducts 72 and 74 (Scheme 17). Hydrolysis of compounds $\mathbf{7 2}$ and $\mathbf{7 4}$ with diluted hydrochloric acid in aqueous acetonitrile gave carbonyl compounds 73 (75\%, product of deethoxylation) and $75(95 \%){ }^{106}$ 


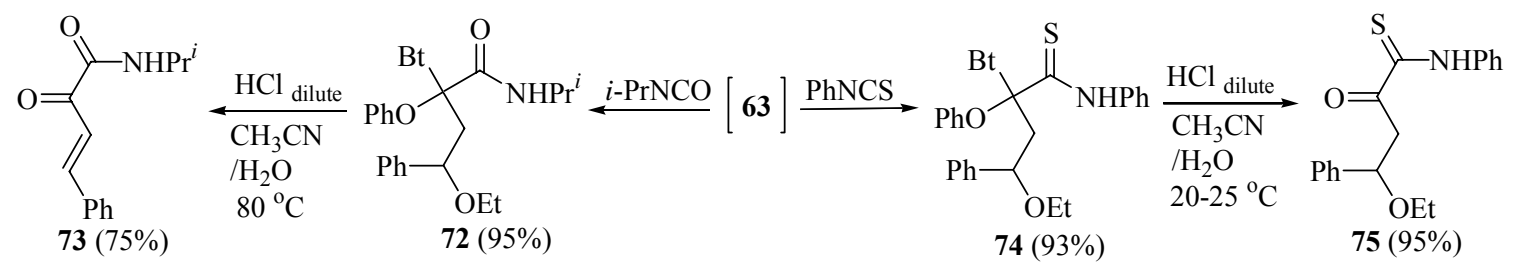

\section{Scheme 17}

\section{2. $N$-[Ethoxy(aryl)methyl]benzotriazoles - aroyl anion synthons}

If an aryl- or heteroaryl- group together with a ethoxy group is already present at the $\alpha$-position to benzotriazole, then the remaining hydrogen is sufficiently acidic to be deprotonated and replaced by a wide variety of electrophiles as shown in Scheme $18 .{ }^{101,107}$

Synthons 78 have been prepared in good yields (51-85\%) either from aldehydes 76 or the corresponding acetals $77 .{ }^{101,107}$ Treatment of $\mathbf{7 8}$ with butyllithium in THF at $-78{ }^{\circ} \mathrm{C}$ for several minutes gave the anions 79; subsequent reaction with an appropriate electrophile, such as alkyl halides, ${ }^{101}$ aldehydes, ${ }^{101}$ ketones, ${ }^{101}$ and imines ${ }^{101}$ at the same temperature for few minutes followed by simultaneous hydrolysis of intermediates 80, 82, 85, and 87 with diluted hydrochloric or sulfuric acid during workup afforded ketones $\mathbf{8 1}, \mathbf{8 3}, \mathbf{8 6}$, and $\mathbf{8 8}$ in good yields. With anion 79 (Ar = 2-pyridyl), reactions with alkyl halides and benzaldehyde were accomplished at room temperature followed by normal hydrolysis of $\mathbf{8 0}(\mathrm{Ar}=2$-pyridyl, $\mathrm{R}=$ alkyl) to ketones $\mathbf{8 1}(\mathrm{Ar}=2$-pyridyl, $\mathrm{R}=$ alkyl) or hydrolysis / self-oxidation of $\mathbf{8 2}(\mathrm{Ar}=2$ pyridyl, $\mathrm{R}=\mathrm{Ph}$ ) to diketone $\mathbf{8 4}$ in $78 \%$ yield.
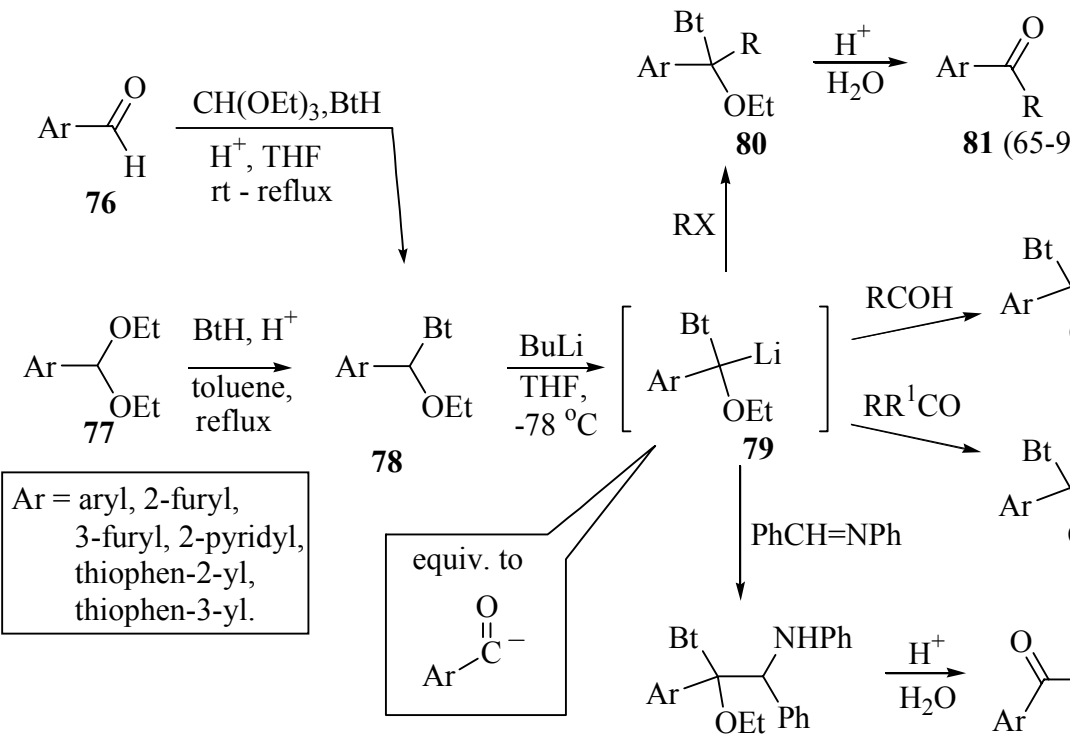

87

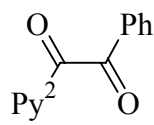

$81(65-99 \%)$
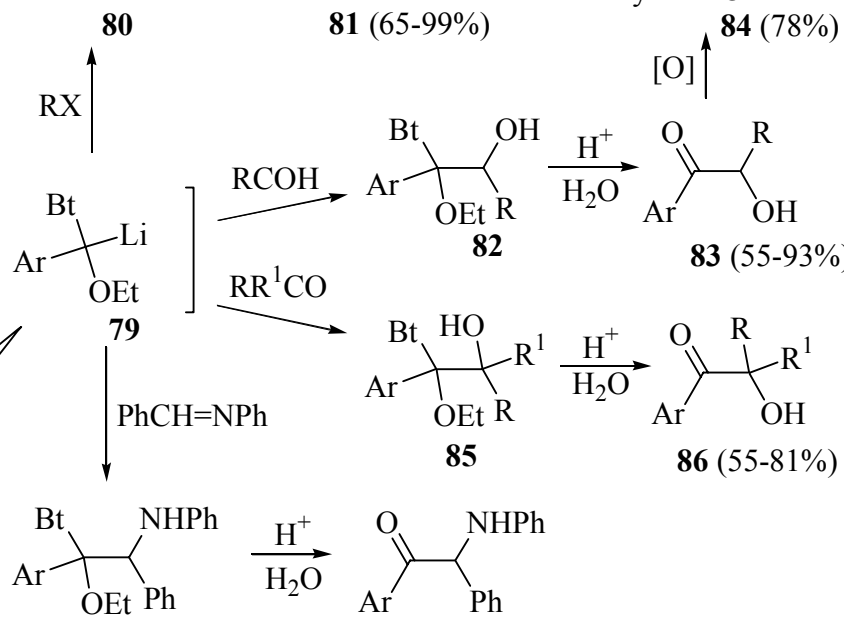

$88(54-83 \%)$

\section{Scheme 18}


Deprotonation of the methine group of $\mathbf{7 8}$ occurs immediately after the addition of butyllithium. The highly reactive anions $\mathbf{7 9}$ are of limited stability in solution, especially in the case of furan and thiophene systems, and therefore immediate quenching with electrophiles is necessary for satisfactory results. Prolonged lithiation times led to partial decomposition of the resulting anion $\mathbf{7 9}$ and subsequently to low yields. Two exceptions are the 2-pyridyl ketones $\mathbf{8 1}$ (Ar = 2-pyridyl, $\mathrm{R}=$ alkyl) and 84 since for these the precursor anion $79(\mathrm{R}=2$-pyridyl) was stable even at $20^{\circ} \mathrm{C}$.

With trialkylsilyl chlorides anions $\mathbf{7 9}$ form intermediates 89; the direct hydrolysis of 89 with dilute hydrochloric or sulfuric acid in aqueous THF give good yields of aroylsilanes $\mathbf{9 0}$ (Scheme 19). ${ }^{107}$

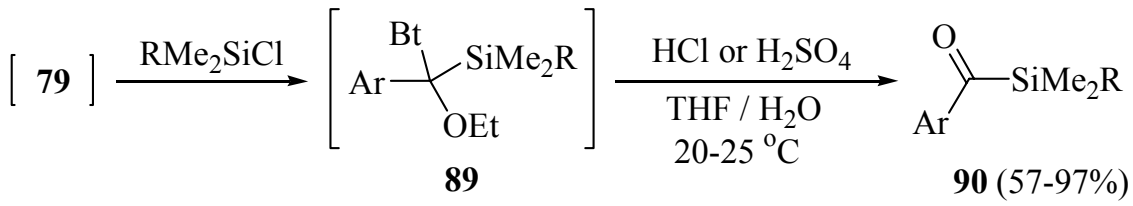

\section{Scheme 19}

\subsection{Bis(benzotriazolyl)methane derivatives}

Bis(benzotriazolyl)arylmethanes 43 (Figure 1, $\mathrm{R}=$ Aryl), available from either substituted benzaldehydes with benzotriazole in the presence of thionyl chloride ${ }^{107}$ or $\alpha, \alpha$-dichlorotoluenes with benzotriazole, ${ }^{108}$ on treatment with LDA $^{109}$ or potassium tert-butoxide ${ }^{110}$ form carbanion stable at temperatures up to $0{ }^{\circ} \mathrm{C}$.

Reactions of anion 92 (generated from 91) with alkyl, benzyl, or allyl halides give alkylated intermediates 93 in good yields (52-95\%, except for product of the reaction with secbutyl bromide, $8 \%$ ), as well as reactions with acid halides and cyclohexenone give good yields of masked diketones 99 and exclusive 1,4-addition product 101, respectively (Scheme 20). ${ }^{110}$ However, treatment of anion 92 with 4-vinylpyridine, chalcone, ethyl acrylate, and acrylonitrile gave no reaction. On the other hand, reaction of 91 with 4-vinylpyridine in the presence of catalytic potassium tert-butoxide (0.05 equiv) in THF at $-10-(-5){ }^{\circ} \mathrm{C}$ gave addition product 103 in $75 \%$ yield. ${ }^{111}$ 


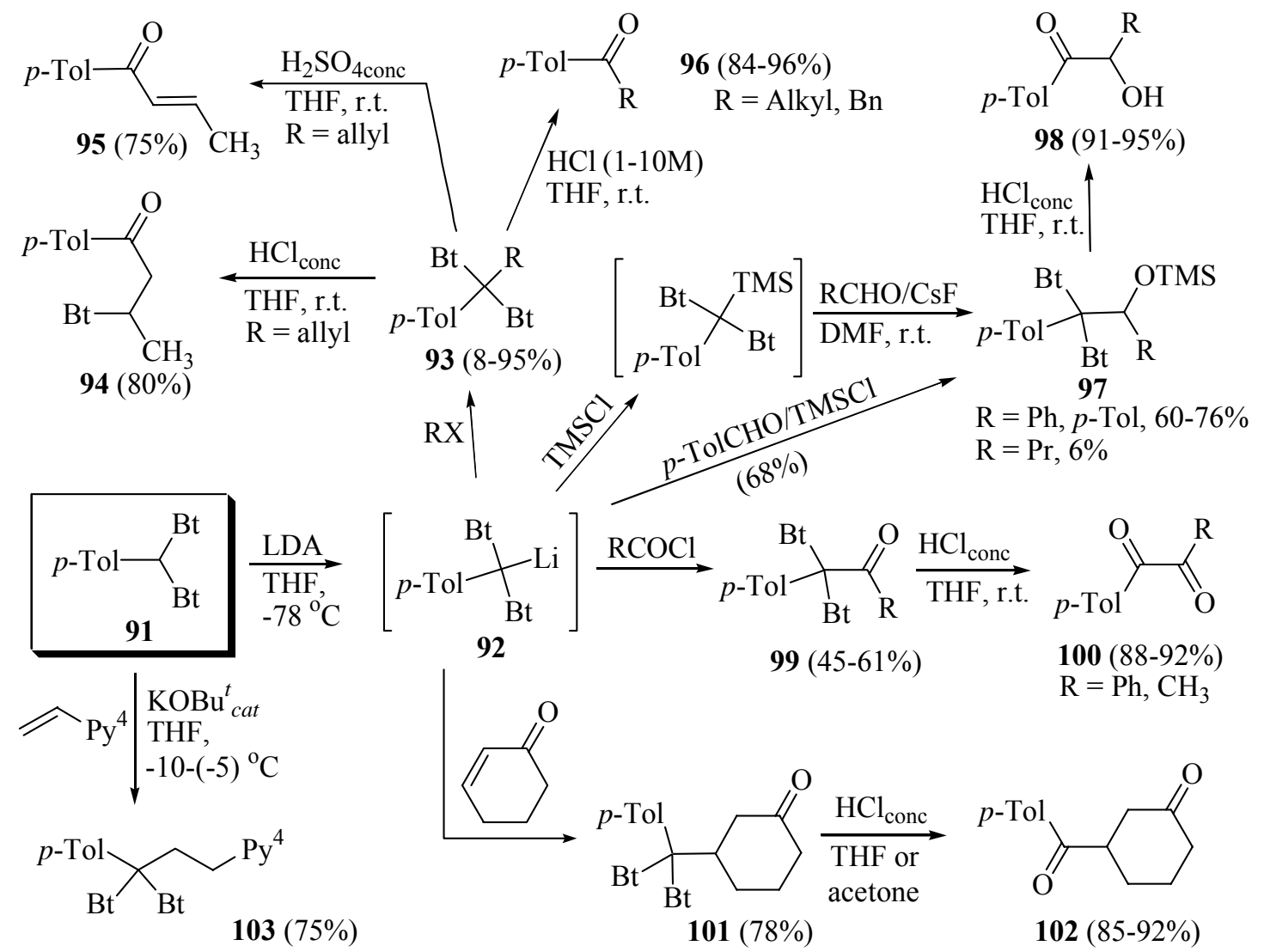

\section{Scheme 20}

Unlike previously discussed synthons 39 and 78, reactions of anion 92 with aldehydes appear to be reversible and result in recovery of starting materials. However, reaction of 92 with $p$-tolualdehyde followed by the addition of trimethylsilyl chloride gave $68 \%$ yield of intermediate silyl ether $97(\mathrm{R}=p$-Tol). Alternatively, compounds 97 were obtained by treatment of anion 92 with trimethylsilyl chloride followed by the reaction with aldehydes in the presence of caesium fluoride in DMF (Scheme 20). ${ }^{110}$

Hydrolysis of intermediates 93, 97, 99, and 101 (except 93, R = allyl) in THF in the presence of hydrochloric acid at $20-25{ }^{\circ} \mathrm{C}$ gives corresponding ketones 96, 98, 100, and 102 in good yields (Scheme 20). Hydrolysis of intermediate $93(\mathrm{R}=$ allyl) was accompanied by the addition of benzotriazole to allyl group resulted in formation of $\beta$-benzotriazolyl ketone 94 $(80 \%)$. In the presence of concentrated sulfuric acid in THF at $20-25{ }^{\circ} \mathrm{C}$, compound $93(\mathrm{R}=$ allyl) gave crotonophenone $95(75 \%){ }^{110}$

Bis(benzotriazolyl)alkanes are also potential alkanoyl anion synthons. The presence of two benzotriazolyl groups in bis(benzotriazolyl)ethane 104 stabilizes carbanion 105 formed on treatment with butyllithium in THF at $-78^{\circ} \mathrm{C}$ (Scheme 21 ). At $-78{ }^{\circ} \mathrm{C}$, carbanion 105 reacts with ketones including enolizable to give, upon quenching with aqueous ammonium chloride at the same temperature, good yields of masked $\alpha$-hydroxyketones 106. However, if the reaction 
temperature is allowed to rise to $20{ }^{\circ} \mathrm{C}$ prior to quenching with aqueous ammonium chloride, the reaction results in recovery of starting material $104 .^{112}$

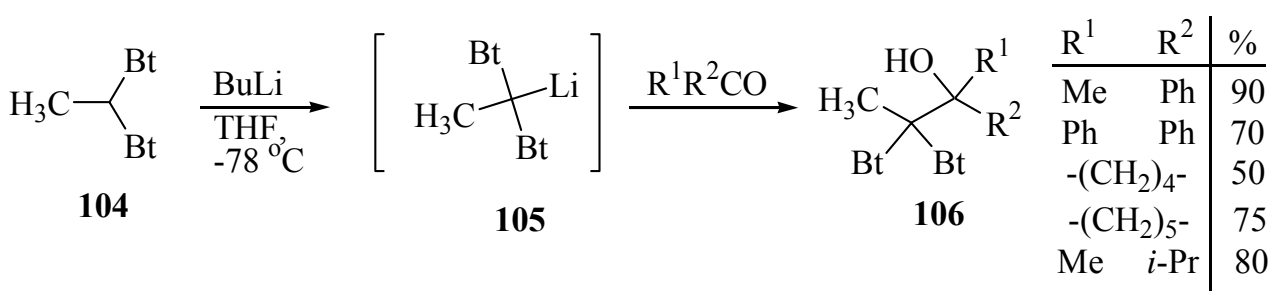

\section{Scheme 21}

\subsection{1-(1-Methylsulfanylalkyl)benzotriazoles}

(Benzotriazol-1-yl)methyl methyl thioether $\mathbf{1 0 7}$ is conveniently accessible from dimethyl sulfoxide, acetic anhydride, and benzotriazole (98\%) (Scheme 22). ${ }^{13}$ On treatment with butyllithium in THF at $-78{ }^{\circ} \mathrm{C} \mathbf{1 0 7}$ gives the carbanion, which reacts smoothly with alkyl halides, including cyclic, benzyl, and allyl, to form intermediates 108 (55-85\%). Compounds 108 can be deprotonated using butyllithium or in some cases LDA to form anions 109, which react further with various electrophiles, such as alkyl halides, carbonyl compounds (quenching of the reaction mixtures is advantageous at $-78{ }^{\circ} \mathrm{C}$ due to reverse to starting materials at temperature approaching $20{ }^{\circ} \mathrm{C}$ ), and phenyl isocyanate to give masked dialkylketones 110 (42-94\%), $\alpha$ hydroxyketones 112 (80-90\%), and 2-ketoamides 114 (ca. 75\%), respectively. With ethyl benzoate, anion $109\left(\mathrm{R}^{1}=\mathrm{Bu}\right)$ gave product $116(40 \%)$ instead of expected 117. With $\alpha, \beta$ unsaturated esters, anions $\mathbf{1 0 9}$ either failed to give or gave low yields of the expected Michael addition products, except the adduct 118 formed in $40 \%$ yield. ${ }^{113}$

Hydrolysis of intermediates 110, 112, 114, and 118 under mild conditions, $20{ }^{\circ} \mathrm{C}$, with dilute aqueous methanolic solution of sulfuric acid (hydrochloric acid for 114) provided corresponding ketones 111, 113, 115, and 119 (Scheme 22). ${ }^{113}$ 


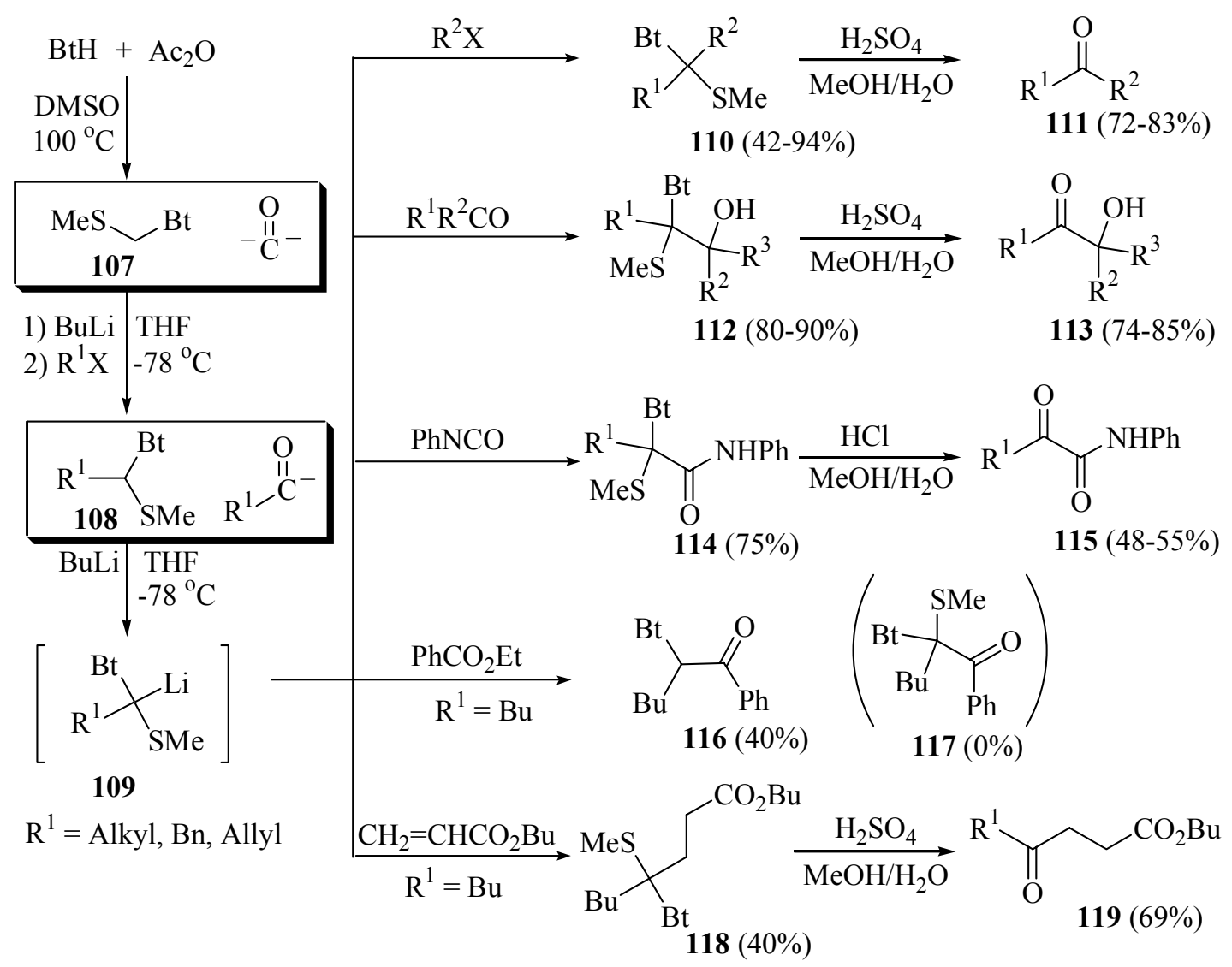

\section{Scheme 22}

\subsection{1-(Carbazolylalkyl)benzotriazoles}

1-(Carbazolylmethyl)benzotriazole 120 on treatment with butyllithium readily formed anion $\mathbf{1 2 1}$, a versatile formyl anion equivalent, ${ }^{114}$ which reacts with variety of electrophiles, including alkyl halides, aldehydes, ketones, isocyanates, isothiocyanates, and esters, to give $71-96 \%$ yields of adducts 122 (Scheme 23). Hydrolysis of intermediates 122 with dilute sulfuric acid in aqueous THF at $20-25{ }^{\circ} \mathrm{C}$ gave corresponding aldehydes 123 , which were trapped and characterized as 2,4-dinitrophenyl hydrazones. ${ }^{114}$

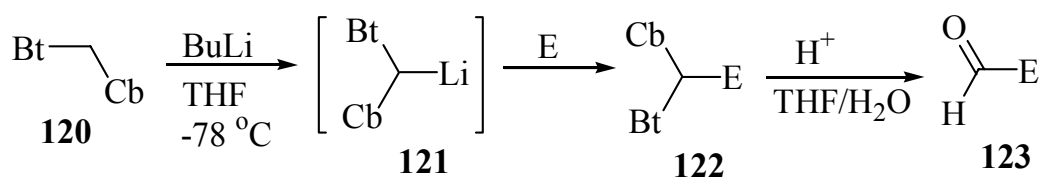

\section{Scheme 23}

Intermediates $122(\mathrm{E}=\mathrm{Alkyl})$ can be further deprotonated and the resulting anions again react with electrophiles. Thus compounds 124 (Scheme 24) with butyllithium in THF at $-78{ }^{\circ} \mathrm{C}$ give anions 125, which further react with electrophiles. ${ }^{115}$ With alkyl halides, $\alpha, \beta$-unsaturated 
ketones, and phenyl and tert-butyl isocyanates, anions 125 give corresponding alkylated products 126, exclusively 1,4-addition products 128, and amides $\mathbf{1 3 3}$. Reactions of $\mathbf{1 2 5}$ with aldehydes showed to be reversible and addition of trimethylsilyl chloride was necessary to trap products of addition as silyl ethers 130. Unlike isocyanates, reaction of anions 125 with phenyl isothiocyanate results in the addition followed by the elimination of benzotriazole to give unsaturated thioamides $\mathbf{1 3 5}$. $^{115}$

Hydrolysis of compounds 126, 128, 130, and 133 (except adduct 130 of tertbutylcarbaldehyde, $\mathrm{R}^{2}=\mathrm{Bu}^{t}$ ) to corresponding ketones 127, 129, 131, and 134 was achieved under mild reaction conditions, at $20-25^{\circ} \mathrm{C}$, using dilute hydrochloric acid in THF (Scheme 24). Treatment of compound $130\left(\mathrm{R}^{2}=\mathrm{Bu}^{t}\right)$ under these conditions resulted in elimination of benzotriazole and formation of product 132, which is resistant to further hydrolysis to $\alpha$ hydroxyketone. ${ }^{115}$

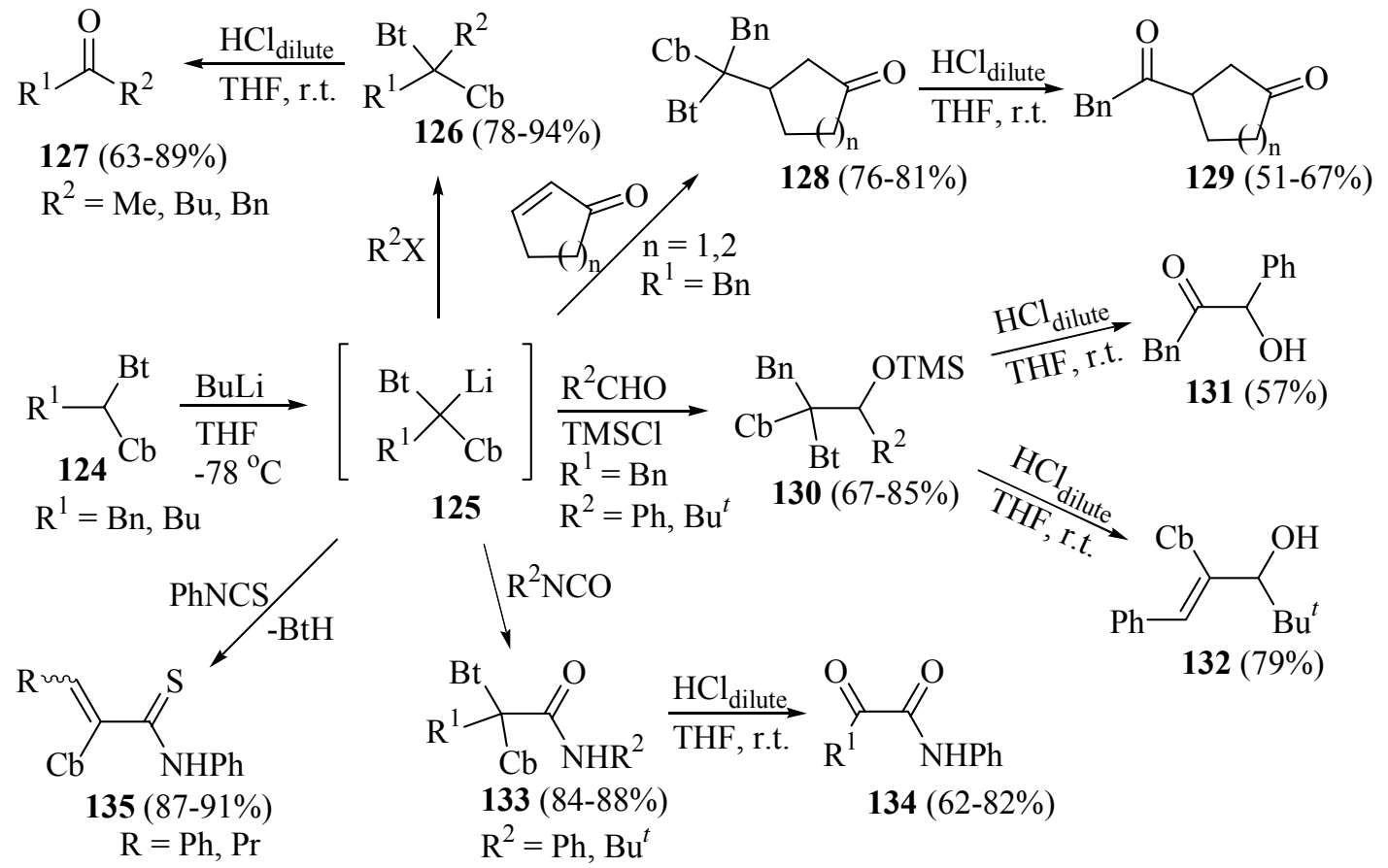

\section{Scheme 24}

\section{$\beta$-Aminoalkanoyl aanion synthons from $N$-vinylcarbazole and $N$ - aminomethylbenzotriazoles}

Alkylaminomethylbenzotriazoles 137 exist in equilibrium with the corresponding immonium cation and add to vinyl group of $N$-vinylcarbazole 136 giving adducts 138 (Scheme 25), which are $\beta$-amino functionalized acyl anion synthons of type 124 (Scheme 24). Compounds 138 on the treatment with butyllithium form anions 139, which further react with alkyl halides, or aldehydes in the presence trimethylsilyl chloride to give intermediates 140 (69-86\%) and 142 (57-68\%), hydrolysis of which with dilute aqueous hydrochloric acid in THF at $20-25{ }^{\circ} \mathrm{C}$ provides 
corresponding $\beta$-amino-functionalized dialkyl- 141 (84-96\%) and $\alpha^{\prime}$-hydroxy- 143 (82-89\%) ketones (Scheme 25). ${ }^{116}$

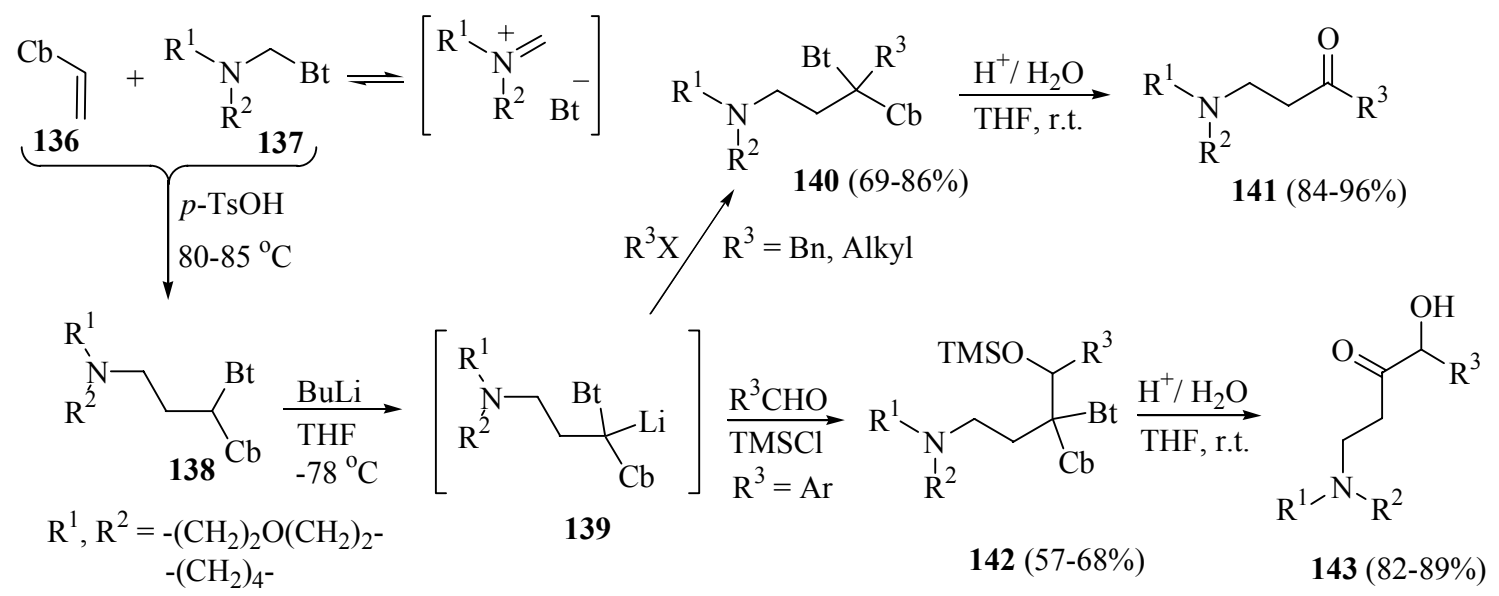

\section{Scheme 25}

\subsection{Application to the synthesis of 1,6-diketones}

An example of the application of benzotriazole mediated acyl anion synthons is shown in the preparation of symmetrical and unsymmetrical alkyl, aryl, alkenyl and alkynyl 1,6-diketones 146 and 150 in Scheme 26. ${ }^{117}$ 1,4-Dibromobutane is reacted with two equivalents of the anion derived from the Bt-reagent 144 to give intermediates 145, which on hydrolysis form the 1,6diketones 146 in high yields. Alternatively, 1,4-dibromobutane is reacted with a single equivalent of the anion of 144, to produce intermediates 147, and then with the anion of the second Bt-reagent 148 to give upon hydrolysis unsymmetrical diketones $\mathbf{1 5 0}$ in good yields. Reaction conditions for hydrolysis of intermediates 145 and 149 depend from nature of groups $\mathrm{R}^{1}$ and $\mathrm{R}^{3}$ : dilute hydrochloric acid in aqueous methanol at room temperature was used for preparation of alkyl diketones, and mixture of oxalic acid, water and silica gel in dichloromethane at room temperature was applied for mild hydrolysis of sensitive alkenyl or alkynyl derivatives. ${ }^{117}$ 

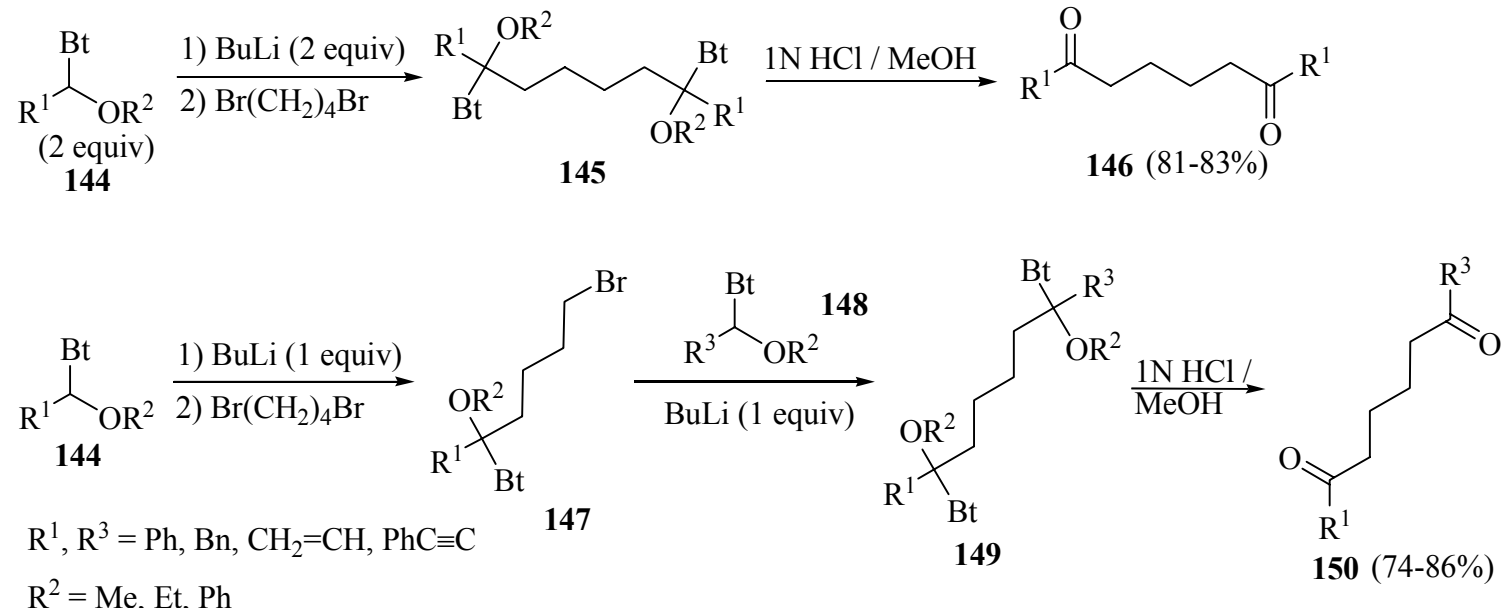

\section{Scheme 26}

\section{Propenoyl anion synthons}

$N$-( $\alpha$-Ethoxyallyl)benzotriazoles 151 are excellent propenoyl-anion synthons. ${ }^{97,107,118-121}$ The starting materials 151a,b are easily accessible from the corresponding acetal and benzotriazole. ${ }^{118-121}$ The lithiated derivatives $\mathbf{1 5 2 a}, \mathbf{b}\left(\mathrm{R}^{1}=\mathrm{H}, \mathrm{Pr}\right)$ react regiospecifically with alkyl halides to form compounds $\mathbf{1 5 3}^{119}$ (Scheme 27), which undergo (without further separation) facile hydrolysis under very mild conditions, such as oxalic acid on wet silica (for $\mathrm{R}^{1}$ $=\mathrm{H})^{119}$ or dilute hydrochloric acid $\left(\mathrm{R}^{1}=\mathrm{Pr}\right),{ }^{121}$ both at $20{ }^{\circ} \mathrm{C}$ to give a variety of vinyl ketones $154(48-82 \%)$.

The lithiated derivatives $\mathbf{1 5 2}$ a,b react with $\alpha, \beta$-unsaturated ketones and esters in reactions which are doubly regiospecific $\alpha$ to the benzotriazole and $\beta$ in the $\alpha, \beta$-unsaturated ketones (esters) to give intermediates of type 163. ${ }^{118,119,121}$ The minor (ca. 20\%) products of 1,2-addition were detected only for addition to $\beta$-substituted vinyl ketones (2-cyclohexenone and hex-4-en-3one). ${ }^{119}$ The intermediates 163 can be hydrolyzed under the same mild conditions to give vinylketoesters and 1,4-diketones of common structure 164 in overall 40-70\% yields. ${ }^{118,119,121}$ Unlike $\alpha, \beta$-unsaturated ketones, $\alpha, \beta$-unsaturated aldehydes, e. g. cinnamaldehyde, with anion $\mathbf{1 5 2 b}$ gave exclusively the product of 1,2-addition $155\left(\mathrm{R}^{2}=\mathrm{PhCH}=\mathrm{CH}-\right)$, the hydroxy group of which can be oxidized with chromic oxide / pyridine to carbonyl followed by hydrolysis to give divinyl 1,2diketone (not shown) in 39\% yield. ${ }^{97}$ 


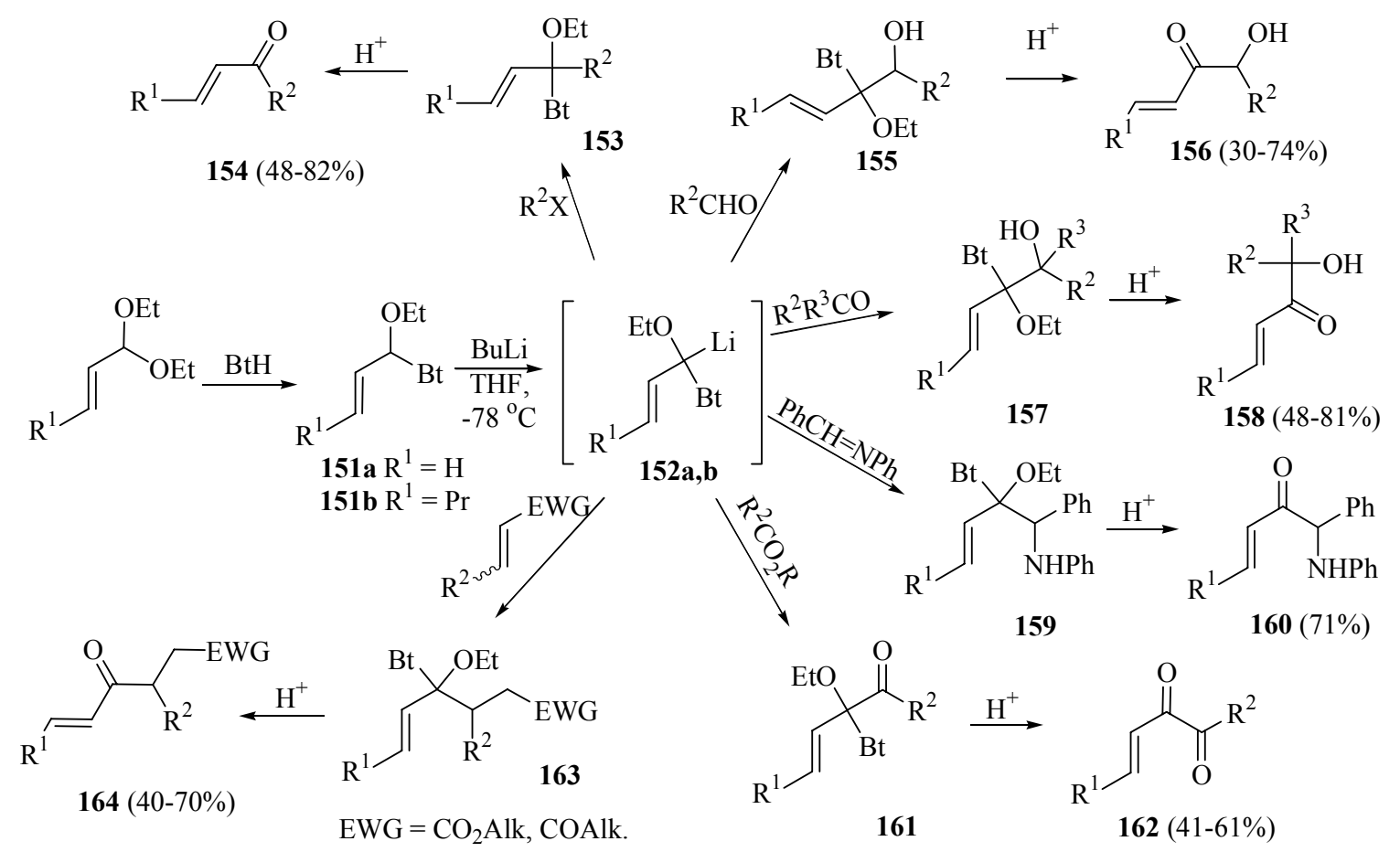

\section{Scheme 27}

The lithiated derivatives $\mathbf{1 5 2 a}$,b react respectively with aldehydes ${ }^{19,121}$ and ketones (except some enolizable or bulky examples, such as heptan-3-one, benzophenone or fluorenone discussed next) ${ }^{120.121}$ to form alcohols 155 and $\mathbf{1 5 7}$, with benzalaniline - to give amine $\mathbf{1 5 9},{ }^{121}$ and with esters of alkyl- or aryl-carboxylic acids - to generate masked diketones $161 .^{97}$ Hydrolysis of these intermediates provides access to $\alpha$-hydroxy vinyl ketones 156 and $158,{ }^{119-} \alpha$ anilinomethyl vinyl ketones $\mathbf{1 6 0},{ }^{121}$ and vinyl 1,2-diketones $\mathbf{1 6 2},{ }^{97}$ respectively.

Reaction of anion 152a $\left(\mathrm{R}^{1}-\mathrm{R}^{3}=\mathrm{H}\right)$, derived from 1-(1-ethoxyallyl)benzotriazole, with trimethylsilyl chloride results in the formation of $\alpha$ - and $\gamma$-substituted products 165 and 166 in ratio 3:1 (Scheme 28). ${ }^{119}$ Reactions of trialkylsilyl halides with $\mathrm{R}^{1}-\mathrm{R}^{3}$ substituted anions 152 followed by hydrolysis with dilute hydrochloric acid in aqueous THF give exclusive formation $\alpha, \beta$-unsaturated acylsilanes $\mathbf{1 6 7} .^{107,122}$

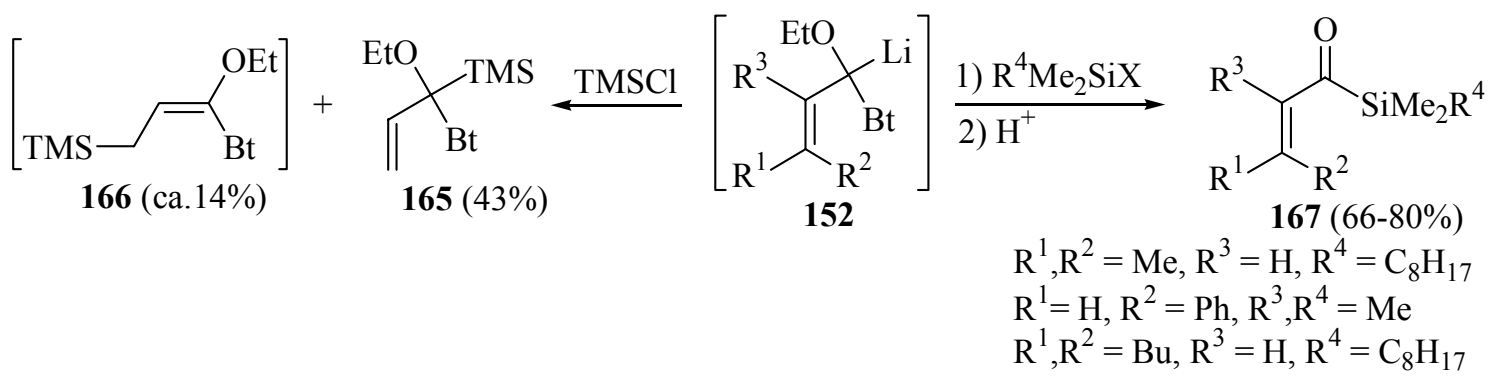

\section{Scheme 28}


Reactions of anion 152a with benzophenone, fluorenone, dicyclohexyl ketone and diisopropyl ketone resulted in exclusive formation of $\gamma$-adducts 168 (Scheme 29). ${ }^{120}$ Treatment of the crude products $\mathbf{1 6 8}$, derived from alkyl ketones, with dilute hydrochloric acid in DMF or methanol at $70{ }^{\circ} \mathrm{C}$, and products from aryl ketones in DMF at $90{ }^{\circ} \mathrm{C}$ gave hydrolysis / cyclization to lactones 169 and hydrolysis / dehydration to unsaturated acids 170, respectively, in good yields.

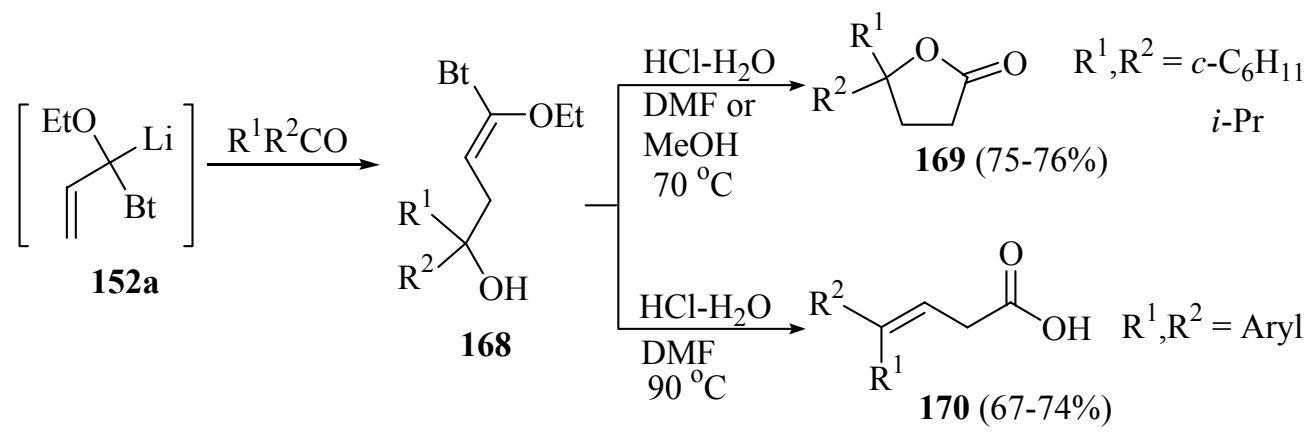

\section{Scheme 29}

Unlike 152a,b, reactions of phenylallyl anion 152c with electrophiles (alkyl halides and carbonyl compounds) produce mixtures of $\alpha$ - and $\gamma$-products 171 and 172 (Scheme 30). Treatment of these mixtures with dilute hydrochloric acid at $20^{\circ} \mathrm{C}$ gave vinyl ketones 173 while compounds 172 (which are masked acids) appeared to be stable under these conditions. ${ }^{121}$ Alkyl halides and aldehydes gave predominantly $\alpha$-products $173(55-79 \%)$ whereas benzyl bromide gave a major $\gamma$-product $172(\mathrm{E}=\mathrm{Bn}){ }^{121}$

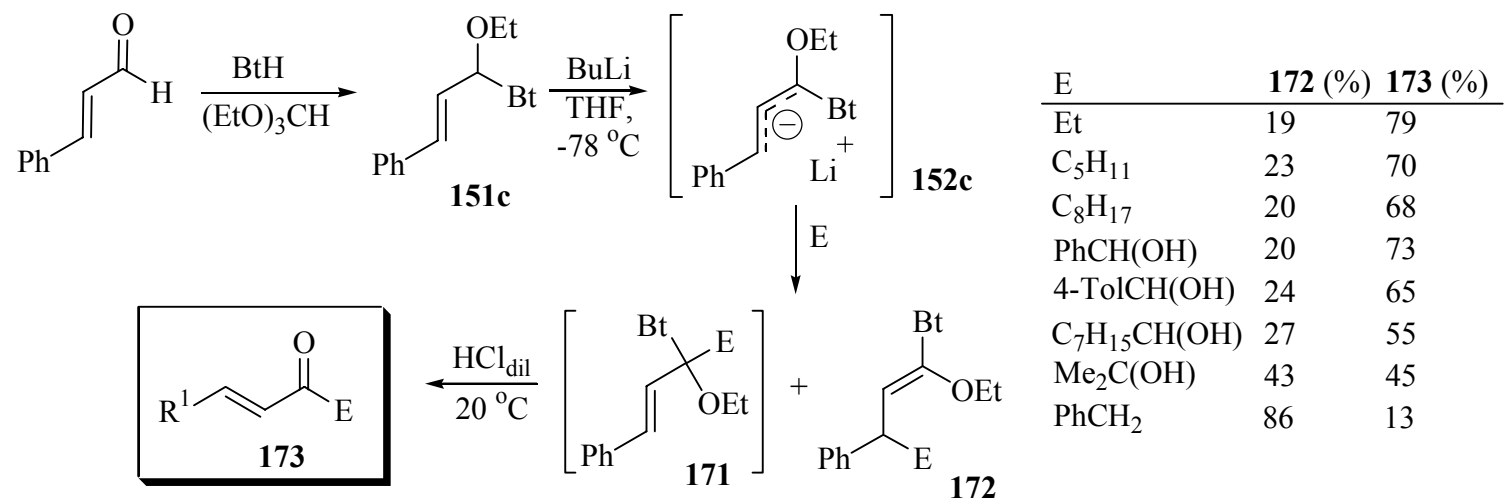

\section{Scheme 30}

Further applications of the propenal acetal- derived Bt-reagent 151a are shown in Scheme 31. ${ }^{122}$ Treatment of $\mathbf{1 5 1 a}$ with catalytic $\mathrm{ZnBr}_{2}$ causes incipient ionization of the benzotriazole anion, which then adds to the ethoxy-stabilized allyl cation, but because of the steric situation 
undergoes rearrangement to give $\mathbf{1 7 4}$. Compound $\mathbf{1 7 4}$ can be lithiated $\alpha$-to the benzotriazole and then alkylated regiospecifically $\alpha$-to the benzotriazole to give $\mathbf{1 7 5}$. Intermediates 175 undergo both hydrolysis to $\alpha, \beta$-unsaturated aldehydes $\mathbf{1 7 8}$ or $\mathrm{S}_{\mathrm{N}} 2$ reaction with Grignard reagents to give allyl ethers 176. This process can be repeated with 175 loosing another proton followed by alkylation $\alpha$-to the benzotriazole to give 177. Intermediates 177 on hydrolysis or reaction with a Grignard reagent give compounds $\mathbf{1 8 1}$ and 179, respectively. Finally, if compound $\mathbf{1 7 7}$ is treated with a small amount of a weak Lewis $\mathrm{Acid}\left(\mathrm{SiO}_{2}\right)$ it will also undergo reversible ionization and an isomerization to form 180. Compounds 180 contain one further acidic proton that can be removed and replaced by an electrophile (alkyl or trialkylsilyl halide) and finally hydrolyzed to give $\alpha, \beta$-unsaturated carbonyl compounds $\mathbf{1 8 2}$. Thus we have five different synthons as shown in Scheme 31.

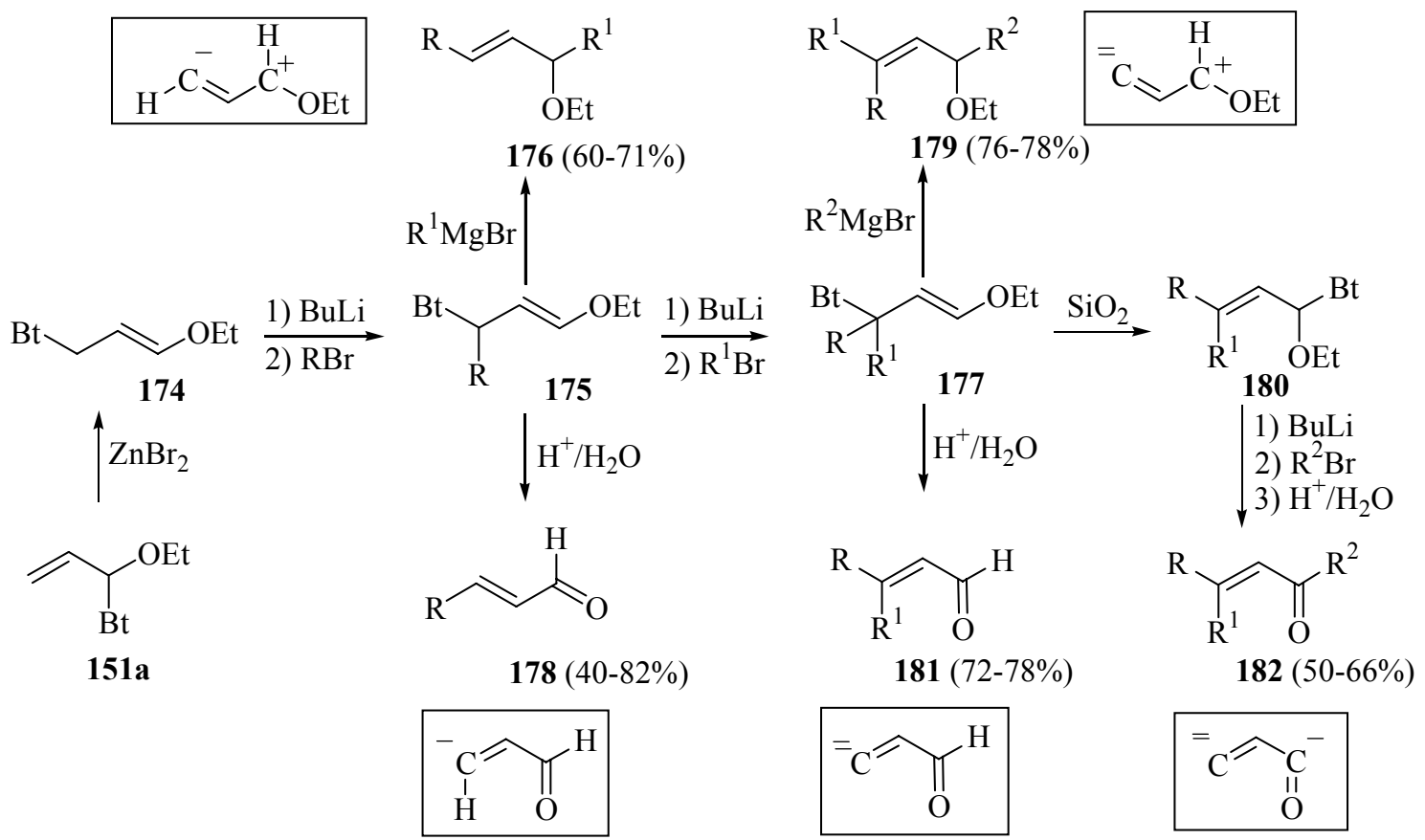

\section{Scheme 31}

\section{Propargoyl anion synthons}

Propargoyl anion synthons $\mathbf{1 8 3}$ are useful for the preparation of various functionalized alkynyl ketones, not easily accessible by other methods (Scheme 32 ). Readily available propargals are activated by the easy replacement of one of the ethoxy groups to give $183 .{ }^{122}$ In 183 the proton $\alpha$ to benzotriazole can be replaced by lithium using n-butyllithium. Anions $\mathbf{1 8 4}$ undergo regioselective alkylation with alkyl halides to give masked ketones $\mathbf{1 8 5} .{ }^{123,124}$ Hydrolysis of $\mathbf{1 8 5}$ with dilute hydrochloric acid provides the corresponding acetylenic ketones $\mathbf{1 8 6} .{ }^{123,124}$ 
Anions 184 can also react with a wide variety of electrophiles. ${ }^{97,107,123,124}$ In each case the electrophile reacts regiospecifically $\alpha$ to the benzotriazole group. Thus, the corresponding adducts 187, 189, 191, 193, 195, and 197 were obtained with aldehydes, ketones, imines, esters, ${ }^{97}$ ethyl carbonate and isocyanates, respectively. ${ }^{123}$ All these intermediates can be isolated and characterized in high yields. However, for the preparation of acetylenic carbonyl derivatives it is not necessary to isolate the intermediates, and hydrolysis can be carried out under mild conditions (typically, dilute hydrochloric acid in acetone (methanol or ethanol) for 10-20 min at 5-20 ${ }^{\circ} \mathrm{C}$ ) to give acetylenic hydroxy ketones 188 and 190, amino-ketones 192, diketones 194, keto-esters 196, and keto-amides 198, respectively, all in high yields (Scheme 32). ${ }^{97,123}$ This kind of compounds were previously little known and requiring rather complex procedures.

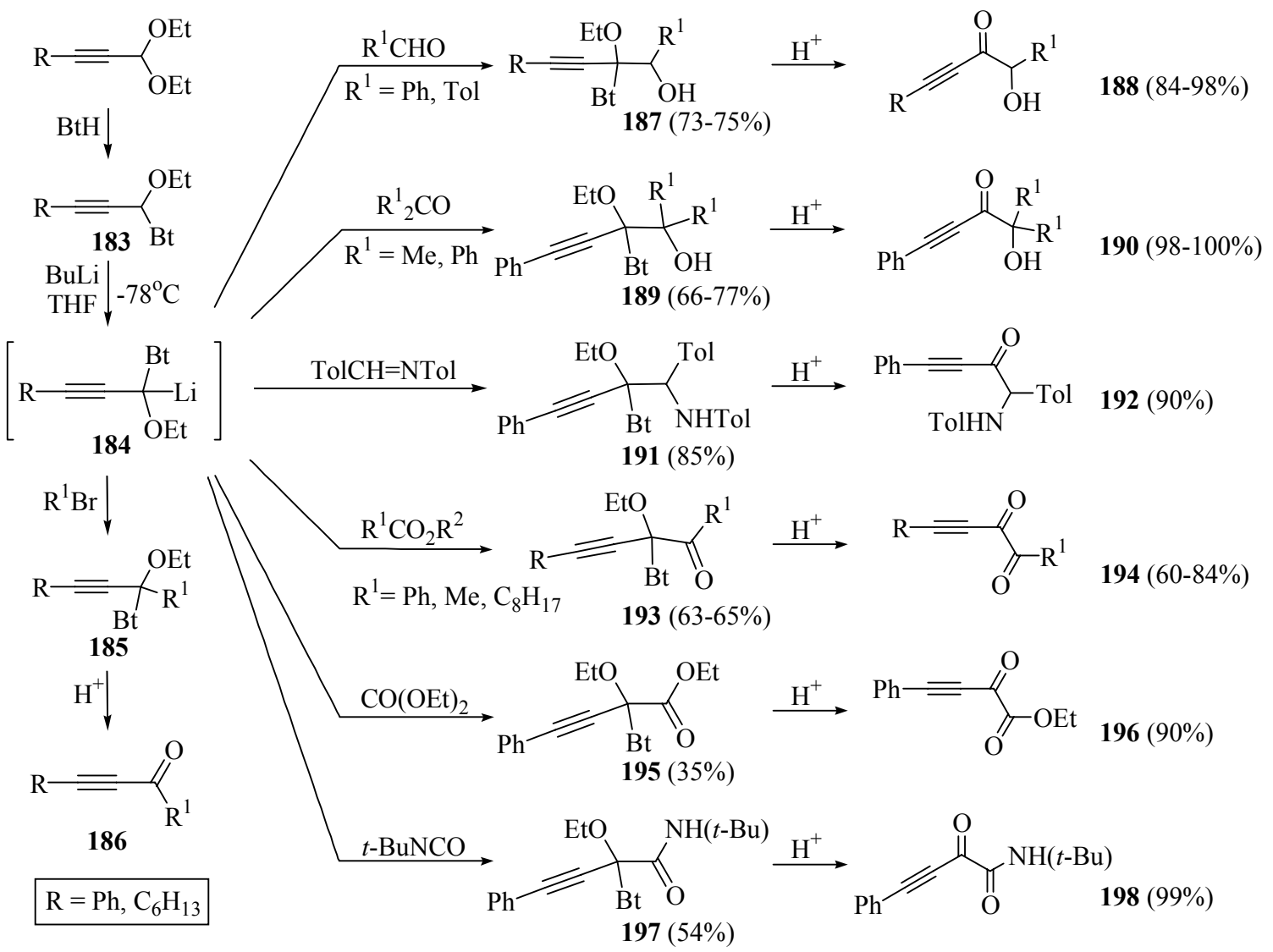

\section{Scheme 32}

A general approach to functionalized acetylenic ketones 202 and propargoyl silanes 204 from 1-(1-ethoxy-propargyl)benzotriazole 199 via synthon 200 is shown in Scheme 33. Successive treatment of 199 with butyllithium / electrophile $\mathrm{E}^{1}$ and again butyllithium / electrophile $\mathrm{E}^{2}$ (TMSCl / butyllithium for 203) followed by hydrolysis of intermediates 201 and 203 provides compounds 202 and $204 .^{107,123}$ 


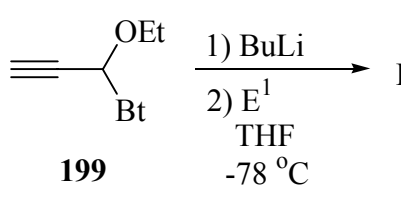

$\mathrm{E}^{1}$ : aldehydes, ketones, TMSCl

$\mathrm{E}^{2}$ : alkyl bromides, aldehydes, imines

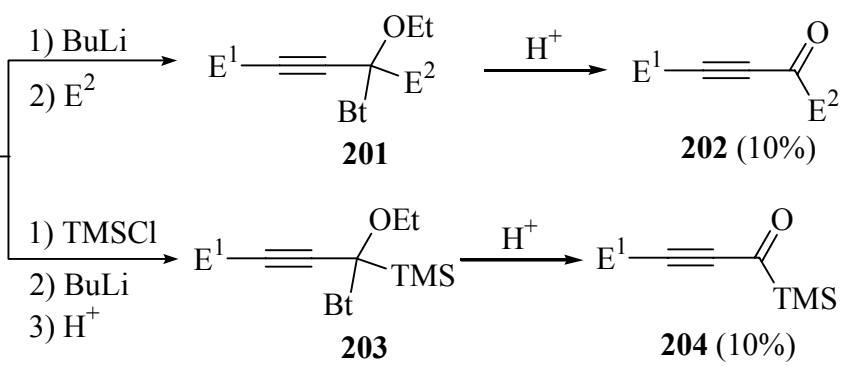

$204(10 \%)$

\section{Scheme 33}

Reactions of anions derived from compounds 183 with trialkylsilyl chlorides followed by acidic hydrolysis with dilute hydrochloric or sulfuric acid in aqueous THF at $20-25{ }^{\circ} \mathrm{C}$ resulted in propargoyl silanes $\mathbf{2 0 6}$ for TMS chloride, or mixture of products 207-209 for octyldimethylsilyl chloride (Scheme 34). Formation of mixture of products 207-209 is presumably caused by steric hindrance of octyldimethylsilyl group and presence of anion 184 in equilibrium with allenic form $\mathbf{2 0 5} .^{107}$

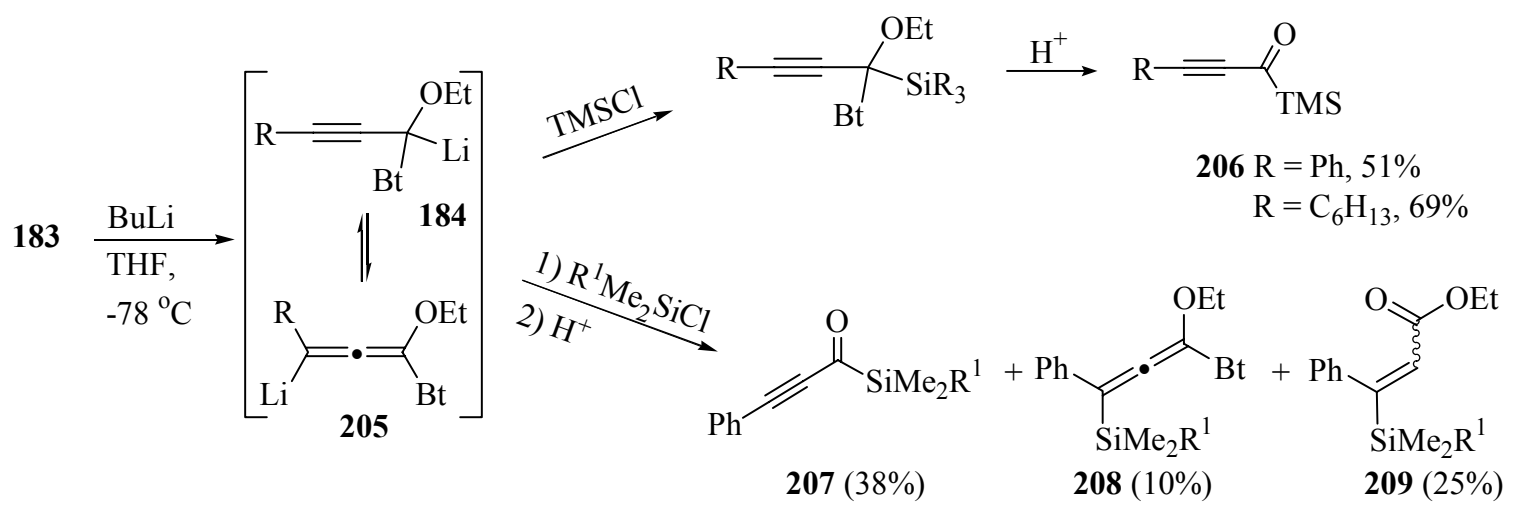

\section{Scheme 34}

Attempted preparation of acetylenic 1,2-diketones of type 194 (where $\mathrm{R}^{1}$ is vinyl) by using $\alpha, \beta$-unsaturated esters and $\alpha, \beta$-unsaturated acid chlorides as electrophiles in the reactions with anions 184 resulted in complicated mixtures (Scheme 32). ${ }^{97}$ On the other hand treatment of anions 184 with trans-cinnamaldehydes gave 1,2-addition products 210 (Scheme 35); oxidation of the hydroxy group in $\mathbf{2 1 0}$ with chromium trioxide / pyridine ${ }^{125}$ and subsequent hydrolysis of 211 with dilute sulfuric acid at $0-25{ }^{\circ} \mathrm{C}$ afforded 1,2-diketones 212 in moderate yields. ${ }^{97}$ 


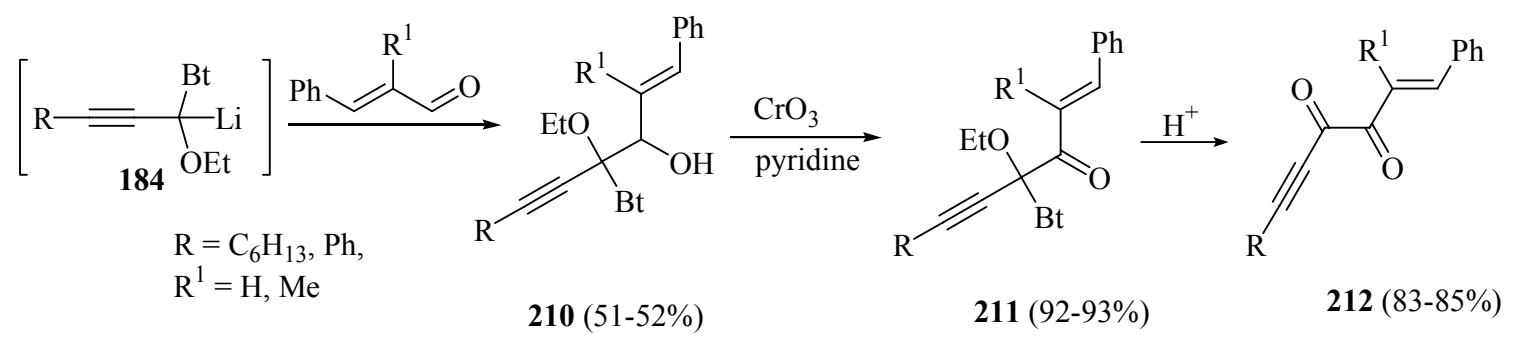

\section{Scheme 35}

Faust and Weber utilized propargoyl synthon 184 for the synthesis of dialkynyl-1,2-diones 215 (Scheme 36). ${ }^{126}$ This approach involves Dess-Martin ${ }^{127,128}$ oxidation of intermediate alcohols 213 to 214 and affords diketones 215 in good yields except for the trimethylsilylsubstituted series $\left(\mathrm{R}^{1}=\mathrm{TMS}\right)$.

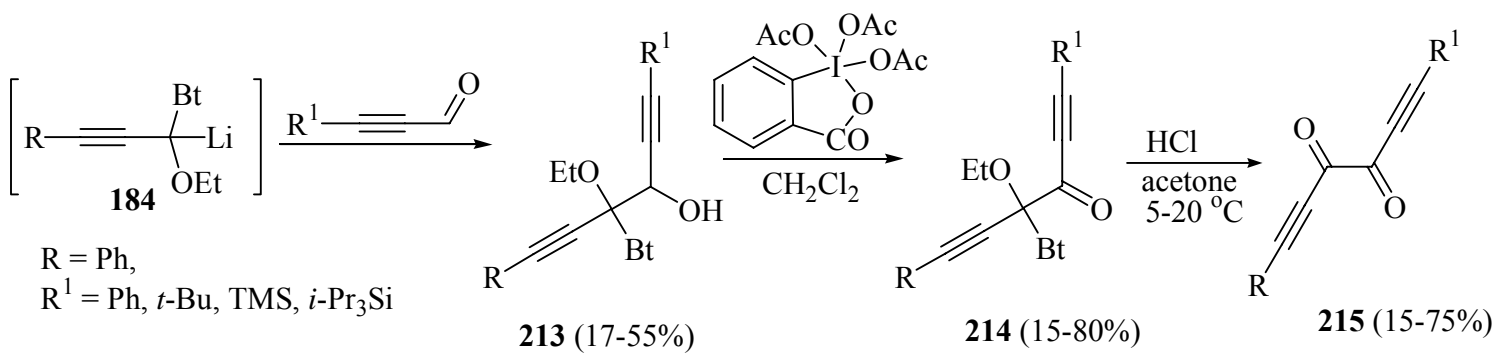

\section{Scheme 36}

\section{Inverted regioselectivity of $\mathbf{1 , 2 , 4 - t r i a z o l e ~ s t a b i l i z e d ~ a l l e n i c ~ a n i o n s . ~}$}

Unlike benzotriazole analog 183, triazole derivative $\mathbf{2 1 6}$ have two acidic protons and on treatment with butyllithium produces allenic dianion 217 (Scheme 37). This dianion reacts with two equivalents of methyl iodide or only one equivalent of less active alkyl bromides to give adducts 218 and 220, direct hydrolysis of which with dilute hydrochloric acid in aqueous ethanol (these compounds undergo hydrolysis even on silica gel) provides $\alpha, \beta$-unsaturated esters 219 and 221, respectively, as mixtures of $E$ and $Z$ isomers. ${ }^{129}$ 


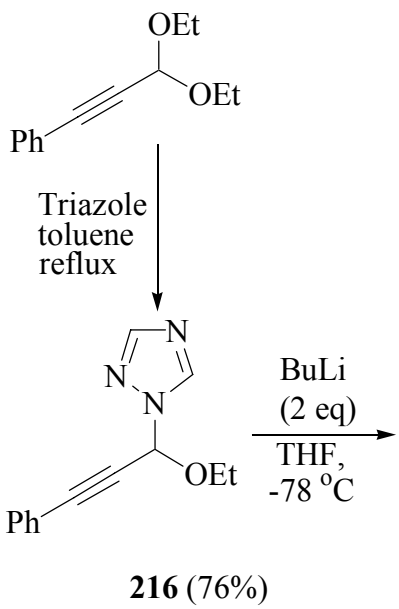

$216(76 \%)$

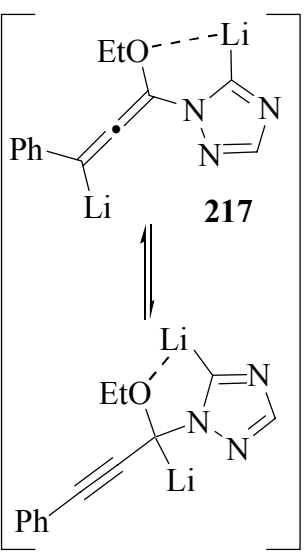

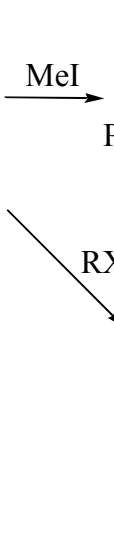

(1)

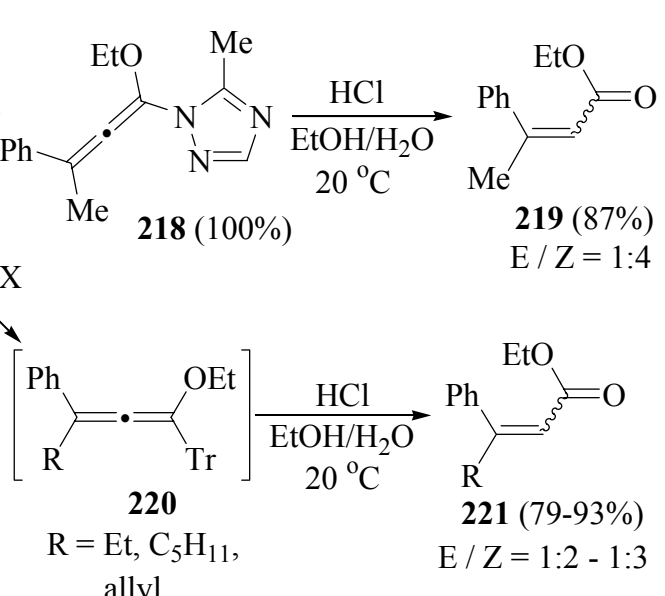

$\operatorname{Tr}=[1,2,4]$ triazol-1-yl

\section{Scheme 37}

Reactions of dianion 217 with two equivalents of carbonyl compounds gave adducts of type 222 with aldehydes, cyclohexanone, and cyclohex-2-enone (exclusively product of 1,2addition) and adduct 224 with one equivalent of benzophenone, which under acidic conditions gave lactones 223, 225-227 (Scheme 38). ${ }^{129}$

Treatment of dianion 217 with imines at $-78{ }^{\circ} \mathrm{C}$ for several minutes produced adduct $\mathbf{2 2 8}$, which on quenching with water at the same temperature and subsequent hydrolysis gave product 229 (Scheme 38). In contrast, prolonged keeping of 228 at $-78{ }^{\circ} \mathrm{C}$ resulted in cyclization by intramolecular substitution of triazole giving pyrrole $\mathbf{2 3 0}$. $^{129}$ 

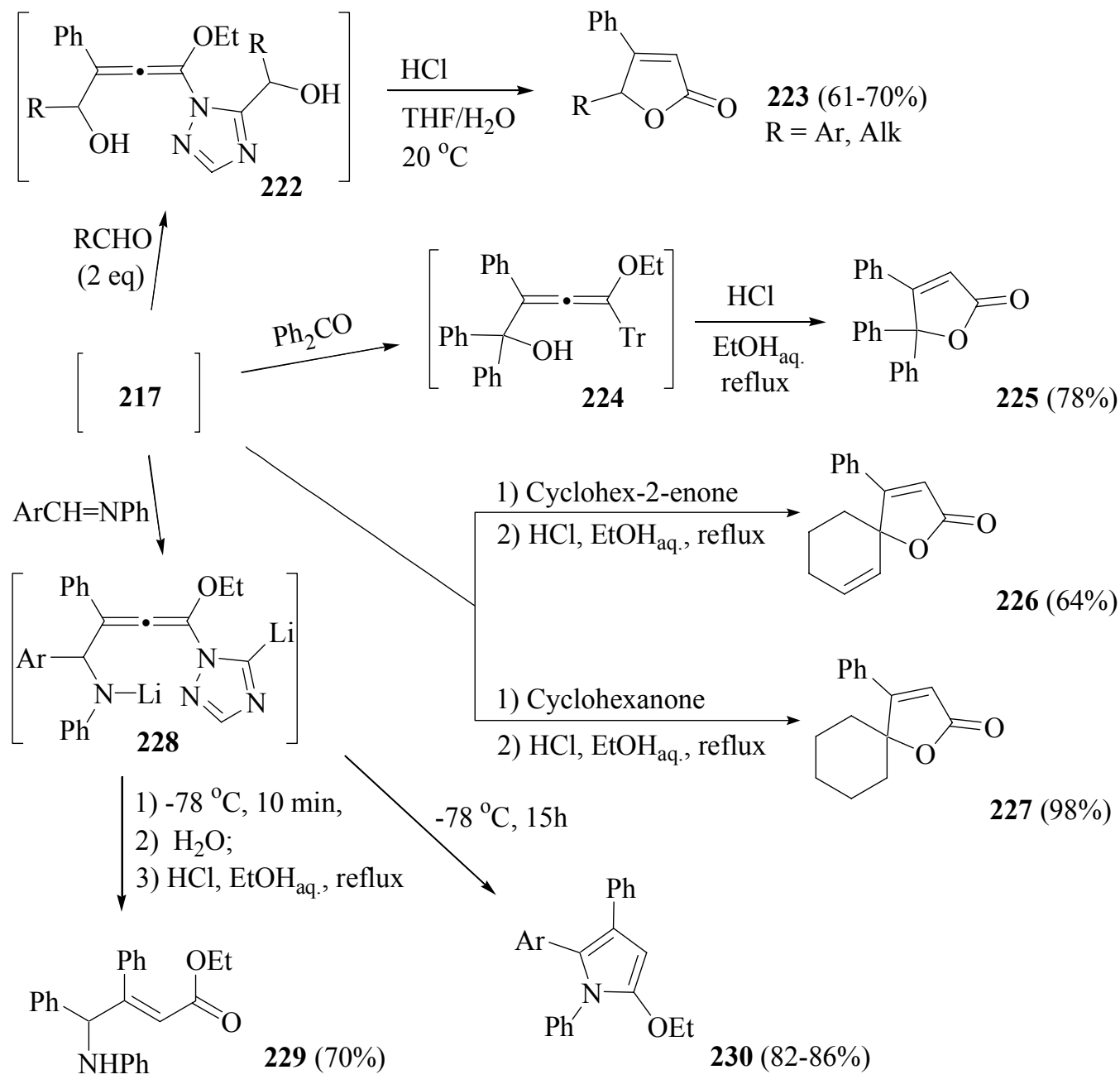

\section{Scheme 38}

Reactions of alkyl acetylene derivative 231 with two equivalents of butyllithium followed by treatment with hexyl bromide, or benzophenone, and hydrolysis gave pairs of products 234 / $\mathbf{2 3 5}$ and $\mathbf{2 3 6} / \mathbf{2 3 7}$, respectively (Scheme 39). Treatment of dianions $232 \rightleftharpoons \mathbf{2 3 3}$ with benzylideneaniline produced exclusively pyrrole $238 .{ }^{129}$ 


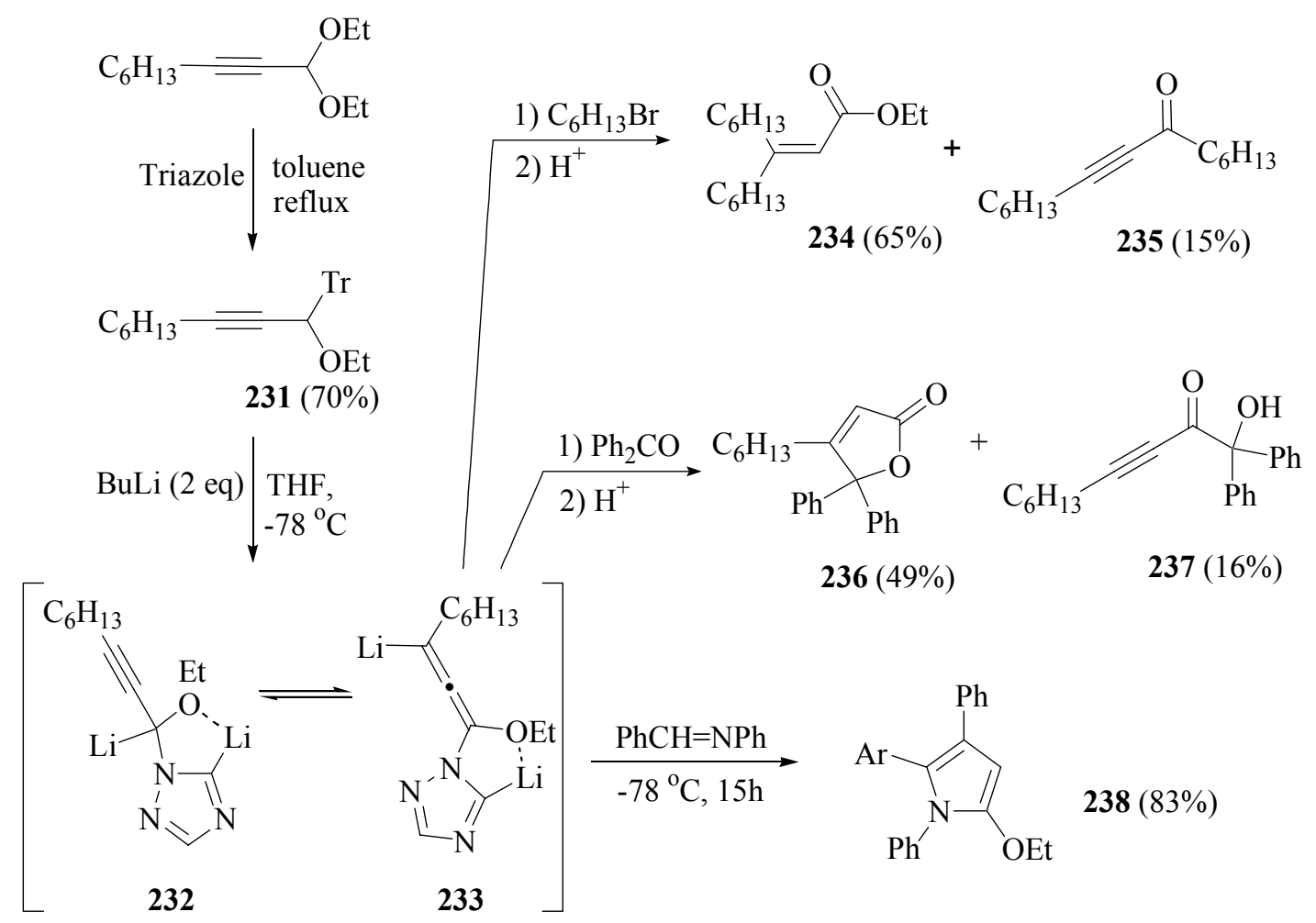

Scheme 39

\section{References and Notes}

1. Froling, A.; Arens, J. F. Recl. Trav. Chim. Pays-Bas 1962, 81, 1009.

2. Truce, W. E.; Roberts, F. E. J. Org. Chem. 1963, 28, 961.

3. Corey, E. J.; Seebach, D. Angew. Chem., Int. Ed. Engl. 1965, 4, 1075.

4. Corey, E. J.; Seebach, D. Angew. Chem., Int. Ed. Engl. 1965, 4, 1077.

5. For a review, see: Seebach, D. Angew. Chem., Int. Ed. Engl. 1979, 18, 239.

6. Ager, D. J. In Umpoled synthons: a survey of sources and uses in synthesis; Hase, T. A., Ed.; Wiley: New York, 1987; p. 19.

7. Yus, M.; Nájera, C.; Foubelo, F. Tetrahedron 2003, 59, 6147.

8. Katritzky, A. R.; Lan, X.; Yang, J. Z.; Denisko, O. V. Chem. Rev. 1998, 98, 409.

9. Stetter, H.; Kuhlmann, H. Organic Reactions 1991, 40, 407.

10. Stetter, H.; Schreckenberg, M. Ger. Pat. 2262343, 1974; Chem. Abstr. 1974, 81, 505015.

11. Stetter, H. Angew. Chem., Int. Ed. Engl. 1976, 15, 639.

12. Jencks, W. P. Catalysis in Chemistry and Enzymology; McGraw-Hill Book Company: New York, 1969.

13. Breslow, R. J. Am. Chem. Soc. 1957, 79, 1762.

14. Breslow, R. J. Am. Chem. Soc. 1958, 80, 3719.

15. Breslow, R.; McNelis, E. J. Am. Chem. Soc. 1959, 81, 3080. 
16. Kuebrich, J. P.; Schowen, R. L.; Wang, M.-s.; Lupes, M. E. J. Am. Chem. Soc. 1971, 93, 1214.

17. Stetter, H.; Rämsch, R. Y.; Kuhlmann, H. Synthesis 1976, 733.

18. Mattson, A. E.; Bharadwaj, A. R.; Scheidt, K. A. J. Am. Chem. Soc. 2004, 126, 2314.

19. Miyashita, A.; Matsuda, H.; Iijima, C.; Higashino, T. Chem. Pharm. Bull. 1992, 40, 43.

20. Miyashita, A.; Matsuda, H.; Higashino, T. Chem. Pharm. Bull. 1992, 40, 2627.

21. Review: Gröbel, B.-T.; Seebach, D. Synthesis 1977, 357.

22. Smith, A. B., III; Adams, C. M. Acc. Chem. Res. 2004, 37, 365.

23. Seebach, D.; Corey, E. J. J. Org. Chem. 1975, 40, 231.

24. Seebach, D.; Wilka, E.-M. Synthesis 1976, 476.

25. Seebach, D.; Bürstinghaus, R.; Gröbel, B.-T.; Kolb, M. Liebigs Ann. Chem. 1977, 830.

26. Orsini, F.; Pelizzoni, F. J. Org. Chem. 1980, 45, 4726.

27. Mori, M.; Chuman, T.; Kohno, M.; Kato, K.; Noguchi, M.; Nomi, H.; Mori, K. Tetrahedron Lett. 1982, 23, 667.

28. Enders, D.; Schüßeler, T. Tetrahedron Lett. 2002, 43, 3467.

29. Fang, J.-M.; Chen, M.-Y. Tetrahedron Lett. 1988, 29, 5939.

30. Smith, A. B., III; Lodise, S. A. Org. Lett. 1999, 1, 1249.

31. Jiang, B.; Chen, Z. Tetrahedron: Asymmetry 2001, 12, 2835.

32. Araki, K.; Suenaga, K.; Sengoku, T.; Uemura, D. Tetrahedron 2002, 58, 1983.

33. Bio, M. M.; Leighton, J. L. J. Org. Chem. 2003, 68, 1693.

34. Sauers, R. R.; Valenti, P. C.; Crichlow, C. A. J. Am. Chem. Soc. 1982, 104, 6378.

35. Erni, B.; Khorana, H. G. J. Am. Chem. Soc. 1980, 102, 3888.

36. Berryhill, S. R.; Price, T.; Rosenblum, M. J. Org. Chem. 1983, 48, 158.

37. Reimer, L. M.; Conley, D. L.; Pompliano, D. L.; Frost, J. W. J. Am. Chem. Soc. 1986, 108, 8010.

38. Ziegler, F. E.; Schwartz, J. A. J. Org. Chem. 1978, 43, 985.

39. Funabashi, M.; Kobayashi, K.; Yoshimura, J. J. Org. Chem. 1979, 44, 1618.

40. Forns, P.; Diez, A.; Rubiralta, M. J. Org. Chem. 1996, 61, 7882.

41. Meyers, A. I.; Tait, T. A.; Comins, D. L. Tetrahedron Lett. 1978, 19, 4657.

42. Blatcher, P.; Warren, S. J. Chem. Soc., Perkin Trans. 1 1979, 1074.

43. Ager, D. J. J. Chem. Soc., Perkin Trans. 1 1986, 183.

44. Mukaiyama, T.; Narasaka, K.; Furusato, M. J. Am. Chem. Soc. 1972, 94, 8641.

45. Alvarez, F. M.; Vander Meer, R. K.; Lofgren, C. S. Tetrahedron 1987, 43, 2897.

46. Corey, E. J.; Seebach, D. J. Org. Chem. 1966, 31, 4097.

47. Blatcher, P.; Grayson, J. I.; Warren, S. J. Chem. Soc., Chem. Commun. 1978, 657.

48. Villa, M.-J.; Warren, S. Tetrahedron Lett. 1989, 30, 5933.

49. Capilla, A. S.; Sánchez, I.; Caignard, D. H.; Renard, P.; Pujol, M. D. Eur. J. Med. Chem. 2001, 36, 389.

50. Ikehira, H.; Tanimoto, S.; Oida, T. J. Chem. Soc., Perkin Trans. 1 1984, 1223.

51. Saigo, K.; Hashimoto, Y.; Kihara, N.; Umehara, H.; Hasegawa, M. Chem. Lett. 1990, 831. 
52. Schill, G.; Jones, P. R. Synthesis 1974, 117.

53. Song, J.; Hollingsworth, R. I. J. Am. Chem. Soc. 1999, 121, 1851.

54. Ogura, K.; Yamashita, M.; Suzuki, M.; Tsuchihashi, G. Tetrahedron Lett. 1974, 15, 3653.

55. Ogura, K.; Yamashita, M.; Furukawa, S.; Suzuki, M.; Tsuchihashi, G. Tetrahedron Lett. 1975, 16, 2767.

56. Fujiwara, K.; Takaoka, D.; Kusumi, K.; Kawai, K.; Murai, A. Synlett 2001, 691.

57. Richman, J. E.; Herrmann, J. L.; Schlessinger, R. H. Tetrahedron Lett. 1973, 14, 3267.

58. Herrmann, J. L.; Richman, J. E.; Schlessinger, R. H. Tetrahedron Lett. 1973, 14, 3271.

59. Fang, J.-M.; Chou, W.-C.; Lee, G.-H.; Peng, S.-M. J. Org. Chem. 1990, 55, 5515.

60. Protective Groups in Organic Synthesis; Greene, T. W. and Wuts, P. G. M.; John Wiley \& Sons: New York, 1999.

61. Rieger, D. L. J. Org. Chem. 1997, 62, 8546.

62. Deprez, P.; Mandine, E.; Vermond, A.; Lesuisse, D. Bioorg. Med. Chem. Lett. 2002, 12, 1287.

63. Muxfeldt, H.; Unterweger, W.-D.; Helmchen, G. Synthesis 1976, 694.

64. Ravindranathan, T.; Chavan, S. P.; Tejwani, R. B.; Varghese, J. P. J. Chem. Soc., Chem. Commun. 1991, 1750.

65. Ohshima, M.; Murakami, M.; Mukaiyama, T. Chem. Lett. 1986, 1593.

66. Schöllkopf, U.; Hänßle, P. Liebigs Ann. Chem. 1972, 763, 208.

67. Baldwin, J. E.; Höfle, G. A.; Lever, O. W., Jr. J. Am. Chem. Soc. 1974, 96, 7125.

68. Soderquist, J. A.; Hassner, A. J. Org. Chem. 1980, 45, 541.

69. Soderquist, J. A.; Hassner, A. J. Am. Chem. Soc. 1980, 102, 1577.

70. Tietze, L. F.; Brill, G. Liebigs Ann. Chem. 1987, 311.

71. Schinzer, D. Synthesis 1989, 179.

72. Gould, S. J.; Remillard, B. D. Tetrahedron Lett. 1978, 19, 4353.

73. Paquette, L. A.; DeRussy, D. T.; Rogers, R. D. Tetrahedron 1988, 44, 3139.

74. Everhardus, R. H.; Gräfing, R.; Brandsma, L. Recl. Trav. Chim. Pays-Bas 1978, 97, 69.

75. Oshima, K.; Shimoji, K.; Takahashi, H.; Yamamoto, H.; Nozaki, H. J. Am. Chem. Soc. 1973, 95, 2694.

76. Bibang Bi Ekogha, C.; Ruel, O.; Julia, S. A. Tetrahedron Lett. 1983, 24, 4825.

77. Ruel, O.; Bibang Bi Ekogha, C.; Lorne, R.; Julia, S. A. Bull. Soc. Chim. Fr. 1985, 1250.

78. Yus, M.; Gutiérrez, A.; Foubelo, F. Tetrahedron 2001, 57, 4411.

79. Cookson, R. C.; Parsons, P. J. J. Chem. Soc., Chem. Commun. 1976, 990.

80. Harirchian, B.; Magnus, P. J. Chem. Soc., Chem. Commun. 1977, 522.

81. Isobe, K.; Fuse, M.; Kosugi, H.; Hagiwara, H.; Uda, H. Chem. Lett. 1979, 785.

82. Cabiddu, M. G.; Cabiddu, S.; Cadoni, E.; Cannas, R.; Fattuoni, C.; Melis, S. Tetrahedron 1998, 54, 14095.

83. Parham, W. E.; Motter, R. F. J. Am. Chem. Soc. 1959, 81, 2146.

84. Trost, B. M.; Hiroi, K.; Kurozumi, S. J. Am. Chem. Soc. 1975, 97, 438.

85. Sato, M.; Takai, K.; Oshima, K.; Nozaki, H. Tetrahedron Lett. 1981, 22, 1609. 
86. Takai, K.; Sato, M.; Oshima, K.; Nozaki, H. Bull. Chem. Soc. Jpn. 1984, 57, 108.

87. Sevrin, M.; Denis, J. N.; Krief, A. Angew. Chem., Int. Ed. Engl. 1978, 17, 526.

88. Raucher, S.; Koolpe, G. A. J. Org. Chem. 1978, 43, 3794.

89. Corey, E. J.; Shulman, J. I. J. Org. Chem. 1970, 35, 777.

90. Krief, A. Tetrahedron 1980 , 36, 2531.

91. Petragnani, N.; Rodrigues, R.; Comasseto, J. V. J. Organomet. Chem. 1976, 114, 281.

92. Piquard, J. L.; Hevesi, L. Tetrahedron Lett. 1980, 21, 1901.

93. Hevesi, L.; Piquard, J.-L.; Wautier, H. J. Am. Chem. Soc. 1981, 103, 870.

94. Katritzky, A. R.; Lang, H.; Wang, Z.; Lie, Z. J. Org. Chem. 1996, 61, 7551.

95. Katritzky, A. R.; Rachwal, S.; Caster, K. C.; Mahni, F.; Law, K. W.; Rubio, O. J. Chem. Soc., Perkin Trans. 1 1987, 781.

96. Katritzky, A. R.; Serdyuk, L.; Xie, L. J. Chem. Soc., Perkin Trans. 1 1998, 1059.

97. Katritzky, A. R.; Wang, Z.; Lang, H.; Feng, D. J. Org. Chem. 1997, 62, 4125.

98. Katritzky, A. R.; Ji, Y.; Fang, Y.; Prakash, I. J. Org. Chem. 2001, 66, 5613.

99. Katritzky, A. R.; Kirichenko, K.; Ji, Y.; Steel, P. J.; Karelson, M. ARKIVOC 2003, vi, 49.

100.Katritzky, A. R.; Kirichenko, K.; Hür, D.; Zhao, X.; Ji, Y.; Steel, P. J. ARKIVOC 2004, vi, 27.

101.Katritzky, A. R.; Lang, H.; Wang, Z.; Zhang, Z.; Song, H. J. Org. Chem. 1995, 60, 7619.

102.Katritzky, A. R.; Rachwal, S.; Rachwal B. J. Chem. Soc., Perkin Trans. 1 1987, 791.

103.Katritzky, A. R.; Rachwal, S.; Rachwal, B. J. Org. Chem. 1989, 54, 6022.

104.Katritzky, A. R.; Bayyuk, S. I.; Rachwal, S. Synthesis 1991, 279.

105.Katritzky, A. R.; Xie, L.; Serdyuk, L. J. Org. Chem. 1996, 61, 7564.

106.Katritzky, A. R.; Feng, D.; Qi, M. J. Org. Chem. 1998, 63, 1473.

107.Katritzky, A. R.; Wang, Z.; Lang, H. Organometallics 1996, 15, 486.

108. Katritzky, A. R.; Kuzmierkiewicz, W.; Rachwal B.; Rachwal, S.; Thomson, J. J. Chem. Soc., Perkin Trans. 1 1987, 811.

109.Katritzky, A. R.; Wu, H.; Xie, L. Tetrahedron Lett. 1997, 38, 903.

110.Katritzky, A. R.; Kuzmierkiewicz, W. J. Chem. Soc., Perkin Trans. 1 1987, 819.

111.Unpublished results by present authors. Treatment of bis(benzotriazolyl)(4methylphenyl)methane 91 with 4-vinylpyridine (1.1 eq.) in anhydrous THF in the presence of catalytic potassium tert-butoxide (0.05 eq.) at $-10-(-5){ }^{\circ} \mathrm{C}$ for $30 \mathrm{~min}$ (deep blue-purple color of the reaction mixture was observed and reaction was complete upon color disappearance) gave 1-[3-(pyridin-4-yl)-1-(4-methylphenyl)-1-(benzotriazol-1yl)propyl]benzotriazole $\mathbf{1 0 3}$ in 75\% yield (purified by column chromatography on silica gel using ethyl acetate / hexanes 1:1), as white prisms from ethyl acetate / hexanes, mp 129-131 ${ }^{\circ} \mathrm{C} ;{ }^{1} \mathrm{H}$ NMR $\delta 8.49(\mathrm{~d}, J=6.0 \mathrm{~Hz}, 2 \mathrm{H}), 8.04(\mathrm{~d}, J=8.1 \mathrm{~Hz}, 2 \mathrm{H}), 7.31-7.17(\mathrm{~m}, 8 \mathrm{H}), 7.14$ $(\mathrm{d}, J=6.0 \mathrm{~Hz}, 2 \mathrm{H}), 6.91(\mathrm{~d}, J=8.3 \mathrm{~Hz}, 2 \mathrm{H}), 3.91-3.85(\mathrm{~m}, 2 \mathrm{H}), 2.81-2.76(\mathrm{~m}, 2 \mathrm{H}), 2.43(\mathrm{~s}$, $3 \mathrm{H}) ;{ }^{13} \mathrm{C}$ NMR $\delta 149.8,149.3,146.5,139.9,132.2,132.0,129.4,128.2,127.8,124.5,123.8$, 120.3, 111.7, 85.7, 42.8, 30.5, 21.1. Anal. Calcd for $\mathrm{C}_{27} \mathrm{H}_{23} \mathrm{~N}_{7}$ : C, 72.79; H, 5.20; N, 22.01 . Found: C, 72.43; H, 5.48; N, 21.99. 
112.Katritzky, A. R.; Bobrov, S.; Kirichenko, K.; Ji, Y. J. Org. Chem. 2004, 69, 303.

113.Katritzky, A. R.; Oniciu, D. C.; Ghiviriga, I.; Soti, F. J. Org. Chem. 1998, 63, 2110.

114.Katritzky, A. R.; Yang, Z.; Lam, J. N. J. Org. Chem. 1991, 56, 2143.

115.Katritzky, A. R.; Yang, Z.; Lam, J. N. J. Org. Chem. 1991, 56, 6917.

116.Katritzky, A. R.; Yang, Z.; Lam, J. N. J. Org. Chem. 1993, 58, 1970.

117.Katritzky, A. R.; Huang, Z.; Fang, Y.; Prakash, I. J. Org. Chem. 1999, 64, 2124.

118.Katritzky, A. R.; Jiang, J. J. Org. Chem. 1995, 60, 6.

119.Katritzky, A. R.; Zhang, G.; Jiang, J. J. Org. Chem. 1995, 60, 7589.

120.Katritzky, A. R.; Jiang, J. J. Org. Chem. 1995, 60, 7597.

121.Katritzky, A. R.; Feng, D.; Lang, H. J. Org. Chem. 1997, 62, 706.

122.Katritzky, A. R.; Wu, H.; Xie, L.; Rachwal, S.; Rachwal, B.; Jiang, J.; Zhang, G.; Lang, H. Synthesis 1995, 1315.

123.Katritzky, A. R.; Lang, H. J. Org. Chem. 1995, 60, 7612.

124.Katritzky, A. R.; Yao, J.; Qi, M. J. Org. Chem. 1997, 62, 8201.

125.Poos, G. I.; Arth, G. E.; Beyler, R. E.; Sarett, L. H. J. Am. Chem. Soc. 1953, 75, 422.

126. Faust, R.; Weber, C. Liebigs Ann. 1996, 1235.

127.Dess, D. B.; Martin, J. C. J. Org. Chem. 1983, 48, 4155.

128.Dess, D. B.; Martin, J. C. J. Am. Chem. Soc. 1991, 113, 7277.

129. Katritzky, A. R.; Feng, D.; Lang, H. J. Org. Chem. 1997, 62, 715.

\section{Authors' biographical data}

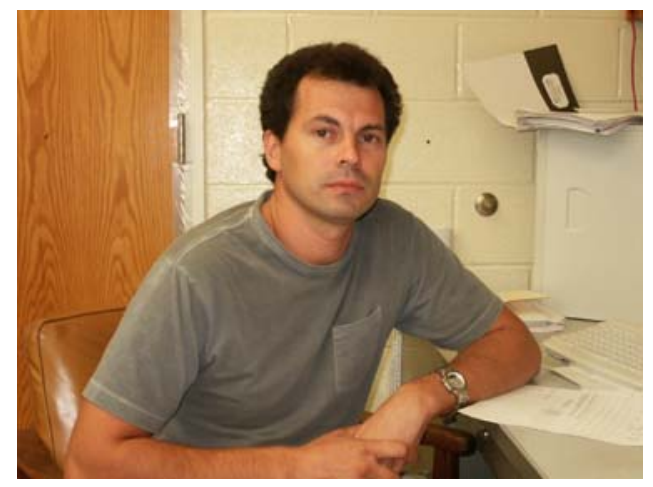

Kostyantyn Kirichenko was born in Severodonetsk (Ukraine) in 1970. He received his MSc degree (1993) in Chemical Technology of Organic Compounds from Ukrainian State ChemicalTechnological University (USCTU, Dnipropetrovsk, Ukraine) and PhD degree (Advisor: Prof. Mati Karelson; 2003) in Organic Chemistry from the University of Tartu (Tartu, Estonia). He worked as a research associate (1993-1996) and later as Assistant Professor (1996-2001) at the Department of Chemical Technology of Organic Compounds at USCTU. In 2001 Dr. Kirichenko joined the research group of Prof. Alan R. Katritzky at the University of Florida with whom he is working on development of new synthetic methodologies for the preparation of heterocyclic 
compounds, homologation - functionalization of carbonyl compounds, and development of Ionic Liquids based on Energetic Azoles.

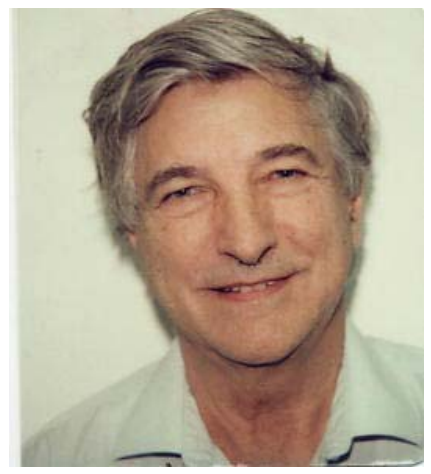

Alan Katritzky was born in London, U.K. and educated at Oxford. He was a Founder Fellow of Churchill College, Cambridge, and then Professor/Dean School of Chemical Sciences at the University of East Anglia before crossing the Atlantic to become Kenan Professor and Director of The Center for Heterocyclic Compounds at the University of Florida in 1980. He has researched, published, lectured, and consulted widely especially in heterocyclic chemistry, synthetic methods, and QSPR. In 2000 he created the non-for-profit foundation ARKAT which publishes "Archive for Organic Chemistry" (Arkivoc) completely free on the Internet. 